\title{
SOBRE LA NO-DOMINACIÓN *
}

\author{
Ian Shapiro *** \\ Universidad de Yale
}

RESUMEN. Mi objetivo en este ensayo es defender una perspectiva de la no-dominación, proponiéndola como una base más adecuada para la justicia que las alternativas existentes. Distingo esa perspectiva de dos tipos de alternativas: aquellas cuyos proponentes rechazan mi afirmación de que la no-dominación es la piedra fundante de la justicia y aquellas que están de acuerdo conmigo pero entienden la no-dominación de otra manera. El primer grupo se divide entre los partidarios de la igualdad, de una parte, y los partidarios de la libertad, de otra parte. Me refiero a sus argumentos en la primera parte del ensayo. Luego me refiero a las concepciones de la no-dominación propuestas por J. Habermas, M. Foucault, M. Walzer, Q. Skinner y Ph. Pettit. Esas visiones tienen varios puntos en común entre sí y con mi propia visión, pero también hay desacuerdos notables. Yo hago explícito lo que está en juego en las formulaciones alternativas, e indico por qué es preferible mi propia concepción, que se enraíza en una visión del poder enfocada en los recursos.

Palabras clave: justicia, dominación, no-dominación, libertad, igualdad, poder basado en recursos.

ABSTRACT. My aim here is to defend a view of non-domination as providing a better basis for justice than the going alternatives. I differentiate it from two kinds of alternatives: those whose proponents reject my claim that non-domination is the bedrock of justice and the who agree with me but understand non-domination differently than I do. The first group divides into partisans of equality, on the one hand, and of freedom, on the other. Their arguments concern me in the first half of the essay. Then I turn to conceptions of non-domination put forward by J. HABERMAS, M. FOUCAULT, M. WALZER, Q. SkINNER and Ph. PetTIT. There is considerable overlap among these various views and between them and mine but there are also notable disagreements. I spell out what is at stake in the alternative formulations, indicating why my own conception, rooted in power- based resourcism, is preferable.

Keywords: justice, domination, non-domination, freedom, equality, resourcism.

* Fecha de recepción: 12 de diciembre de 2012. Fecha de aceptación: 21 de diciembre de 2012.

Originalmente publicado como «On Non-Domination», University of Toronto Law Journal, núm. 62, 2012, 293-336. Traducción de M. ${ }^{a}$ P. SAFFON (Universidad de Columbia en Nueva York).

** Este ensayo es el prolegómeno de un trabajo más extenso titulado Justice against Domination, que será publicado por Harvard University Press. El ensayo cobró vida como la cátedra inaugural B. BARRY, dictada en el London School of Economics en mayo de 2010. El ensayo no se refiere al trabajo de BARRY, y supongo que este habría estado en desacuerdo con buena parte del texto. Pero espero y creo que él no habría considerado que esto descalificaría al ensayo del propósito asignado. No había nada que le gustara más a Brian que la discusión animada. Versiones subsecuentes del ensayo han sido discutidas en reuniones en Yale, la convención de 2010 de la American Political Science Association, Oxford, la Universidad de Cape Town, y las Facultades de Derecho de Cornell y la Universidad de Toronto. Gracias a todas las personas que hicieron comentarios; las advertencias usuales son pertinentes. 


\section{1. ¿POR QUÉ LA NO-DOMINACIÓN?}

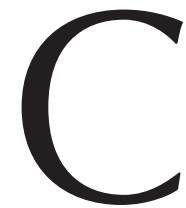

uando la gente experimenta la dominación con frecuencia se queja de injusticia, y ello con razón. En este ensayo, mi objetivo es desarrollar una versión de la no-dominación como la piedra fundante de la justicia que explica, y expande, esta queja común. Dudo que una concepción de la justicia que no fuese hostil a la dominación de manera inequívoca pudiera conseguir muchos adeptos o mantenerlos por largo tiempo, incluso si los atrapase durante algún rato. La gente exige justicia para escapar de la dominación. Yo estoy de acuerdo con la tradición de la filosofía política, que se extiende al menos desde PLATÓN hasta RAWLS, en la cual la justicia es vista como la primera virtud de las instituciones sociales ${ }^{1}$. Si tengo razón en cuanto a las relaciones entre la justicia y la no-dominación, entonces en un sentido importante la no-dominación se convierte en el valor político primario.

Anteriormente he argumentado que el mejor camino para buscar la justicia, así concebida, es democratizar las relaciones humanas de un modo particular. Esto implica institucionalizar la democracia como un bien condicionante o subordinado que moldea las formas en las cuales las personas buscan otros bienes. Mi concepción democrática de la justicia es definida en parte de manera contextual, en conexión con la naturaleza de los bienes en cuestión y las formas en las cuales las personas los buscan en escenarios históricos particulares. Pero el mío es también en parte un ideal general. Este ideal implica, como restricciones a la forma en que las personas buscan conseguir sus metas contextualmente definidas, la necesidad de participación en la toma de decisiones y la existencia de derechos para la oposición. Cuán robustas deberían ser estas restricciones depende de qué tan vulnerables a la dominación sean las personas en escenarios particulares; cuanto más vulnerables sean, más exigentes deberían ser las restricciones.

En mi concepto, la vulnerabilidad a la dominación se operacionaliza principalmente con referencia a la noción de intereses básicos. Las personas tienen intereses básicos en la seguridad, la nutrición, la salud y la educación que son necesarias para que una persona se desarrolle y viva como un adulto normal. Esto incluye el desarrollo de las capacidades necesarias para que las personas funcionen efectivamente en el sistema económico, tecnológico, e institucional prevaleciente, organizado como una democracia, a lo largo de sus vidas ${ }^{2}$. En escenarios colectivos, las personas son más vulnerables cuando sus intereses básicos, así concebidos, están en juego que cuando no lo están. Si yo controlo recursos que usted necesita para reivindicar sus intereses básicos, ello me da poder sobre usted. Este hecho hace legítimo que las restricciones democráticas sobre nuestros esfuerzos colectivos sean más estrictas cuando hay intereses básicos en juego que cuando no los hay ${ }^{3}$. Esta visión del poder enfocada en los recursos, como la

1 Platón, República, traducido al castellano por A. Camarero, Buenos Aires, EUDEBA, 1973, Libro IV, secciones 426e-428d, 248-251 102-103, secciones 443a-e, 273-274; J. RAWLS, Teoría de la Justicia, trad. M. ${ }^{a}$ D. GoNZÁLEZ, Buenos Aires, Fondo de Cultura Económico, 1993, 1. a reimp., 19 (citado en adelante como RAWLs, Teoría).

2 I. Shapiro, Democratic Justice, New Haven, CT, Yale University Press, 1999, $85-86$ (citado en adelante como SHAPIRO, Democratic Justice).

3 Digo que la vulnerabilidad a la dominación se operacionaliza principalmente con referencia a la noción de intereses básicos porque la dominación puede ocurrir de otras maneras también, como cuando alguien amenaza de chantaje a un homosexual que está en el clóset o a alguien que está teniendo un romance secreto. 
he llamado, está orientada a mitigar las formas más serias de dominación que permean los arreglos sociales de los seres humanos ${ }^{4}$.

En este ensayo, mi meta es distinguir esta visión de dos tipos de alternativas: aquellas cuyos proponentes rechazan mi afirmación de que la no-dominación es la piedra fundante de la justicia y aquellas que están de acuerdo conmigo pero entienden la no-dominación de otra manera. El primer grupo se divide entre los partidarios de la igualdad, de una parte, y los partidarios de la libertad, de otra parte. Como yo, en general los igualitaristas consideran que escriben sobre la justicia, principalmente en el marco del debate relacionado con la pregunta cigualdad de qué?, que fue engendrado por la afirmación de A. SEN de que los debates sobre la justicia son siempre, en el fondo, debates sobre algún tipo de igualdad ${ }^{5}$. A veces, los defensores de la libertad son menos claros en cuanto a la relación de su ideal con la justicia, o al menos lo son de manera menos explícita, quizás porque algunos de ellos son escépticos con respecto a la propia idea de justicia ${ }^{6}$. Con independencia de si conciben la libertad como una característica de la justicia o como una alternativa a ella, estos autores tratan a la libertad como el parámetro principal para evaluar la legitimidad de las instituciones políticas. Para los propósitos presentes, supondré que, como R. NOzicK, los partidarios de la libertad ven en su comprensión particular de ésta la base fundante de la justicia ${ }^{7}$. Los simpatizantes de la igualdad ocupan mi atención en la sección II, seguidos por los partidarios de la libertad en la sección III. Luego de explicar por qué la no-dominación es un ideal fundacional preferible que aquellos defendidos en cada uno de esos ámbitos, en la sección IV me refiero a las concepciones de la no-dominación que compiten con la mía, propuestas por J. Habermas, M. Foucault, M. Walzer, Q. Skinner, y Ph. PETTiT. Esas visiones tienen varios puntos en común entre sí y con mi propia visión, pero también hay desacuerdos notables. Yo hago explícito lo que está en juego en las formulaciones alternativas, e indico por qué es preferible mi propia concepción, que está enraizada en una visión del poder enfocada en los recursos.

\section{JUSTICIA, IGUALDAD Y NO-DOMINACIÓN}

Si la no-dominación es la piedra fundante de la justicia, uno podría preguntar de manera razonable si su atractivo explota un compromiso previo con la igualdad. Según

Sin duda hay otras razones para proscribir el chantaje, pero un compromiso con la no-dominación también lo proscribiría.

${ }^{4}$ I. SHAPIRO, La teoría de la democracia en el mundo real, traducción al castellano de J. URDÁNOZ y S. GALLEGO, Madrid, Marcial Pons, 2011, 274 (citado en adelante como SHAPIRO, Mundo real).

5 Vid. A. SEN, «Inequality Reexamined», Documento Ocasional, núm. 2, Yale University, 1989, 15; vid. también el libro de SEN, Nuevo examen de la desigualdad, traducido al castellano por A. M. ${ }^{a}$ BRAvo, Madrid, Alianza Editorial, 1995. Para una crítica, vid. J. KANE, «Justice, Impartiality, and Equality: Why the Concept of Justice Does Not Presume Equality», Political Theory, núm. 24, 1996, 375. Para la respuesta de SEN, vid. A. SEN, «On the Status of Equality», Political Theory, núm. 24, 1996, 394 (citado en adelante como SEN, «Status»); y para la refutación de KANE, vid. J. KANE, «Basal Inequalities: Reply to Sen», Political Theory, núm. 24, 1996, 401 (citado en adelante como KANE, «Basal Inequalities»).

6 Vid. F. A. HAYEK, El espejismo de la justicia social, traducido al castellano por L. REIG AlBIOL, Madrid, Unión Editorial, 1978-1982.

7 R. NozicK, Anarquía, Estado, y utopía, traducido al castellano por R. TAmaYo, México, Fondo de Cultura Económico, 1988 (citado en adelante como NOZICK). 
esta visión, el atractivo moral de la no-dominación es en realidad el atractivo moral de la igualdad. Si eso fuera cierto, entonces podríamos utilizar de mejor manera la energía gastada en justificar la no-dominación ofreciendo una justificación del igualitarismo del cual depende aquella en última instancia. Esta aproximación me parece, sin embargo, poco recomendable, en parte porque la no-dominación sólo está asociada con la igualdad de manera trivial, y en parte porque defender la no-dominación en lugar de la igualdad permite evitar un número de dificultades filosóficas y políticas relacionadas con el igualitarismo.

Cuando digo que el igualitarismo sólo está asociado de manera trivial con la nodominación tal como yo la concibo, no tengo la intención de negar que haya un sentido último en el cual quienes proponen la no-dominación reconocen la igualdad moral de las personas - lo que SEN describe como igualdad elemental - ${ }^{8}$. Pero el trabajo pesado en mi argumento lo hace la idea de no-dominación, no la de igualdad. Tampoco niego que un compromiso con la no-dominación tenga implicaciones distributivas, algunas de las cuales - como veremos- congeniarán con muchos de quienes se consideran igualitaristas. Pero sí quiero negar que la raison d'être de la no-dominación sea promover la igualdad. Estoy de acuerdo con J. KANE en que no hay nada en el significado de justicia que implique una presunción igualitaria ${ }^{9}$. Los arreglos distributivos igualitarios son deseables desde el punto de vista de la justicia sólo cuando están al servicio de la meta de la no-dominación.

Entre los teóricos políticos contemporáneos, al menos desde J. RAWLS, ha existido una tendencia influyente a negar esto; a pensar que la justicia empieza con una presunción a favor de la igualdad. Bajo escrutinio, la naturaleza de ese supuesto vínculo resulta escurridiza. A veces RAWLS escribe como si ese vínculo estuviese incrustado en el propio significado de justicia, tal y como lo muestra su examen de nuestras intuiciones sobre la justicia a través de la posición original, en el cual los lectores eran invitados a especular sobre la justicia mientras se les negaba el conocimiento de sus circunstancias particulares. Un posible camino diferente hacia la igualdad es el incisivo argumento de RAWLS de que las diferencias que existen entre nosotros son moralmente arbitrarias, tengan ellas origen en nuestra naturaleza o en nuestra crianza. Una tercera base potencial para la presunción en favor de la igualdad es la interpretación kantiana formulada por RAWLS de los principios de justicia como expresiones procedimentales del imperativo categórico. Un último camino posible desde la justicia hacia la igualdad pasa por la advertencia de RAWLS de que el estado debería ser neutral frente a diferentes concepciones permisibles de la buena vida. A continuación lidio con cada uno de estos caminos.

\subsection{A la posición original y la lógica de la justicia}

La estrategia de RAWLS consistente en razonar tras un velo de ignorancia no genera un compromiso con la igualdad; más bien supone la aceptación previa de una presunción igualitarista. Su argumento es que, bajo condiciones de escasez moderada, el

\footnotetext{
8 SEN, «Status», op. cit., 395-396.

9 KANE, «Basal Equalities», op. cit., 403-405.
} 
principio de razón insuficiente que opera tras el velo de ignorancia llevaría a cualquier persona racional a escoger la igualdad, salvo que pudiera mostrarse que una distribución desigual operaría en beneficio de todo el mundo ${ }^{10}$. Pero la posición original es un mecanismo expositivo, no un argumento en pro de la igualdad ni, de hecho, en pro de ningún otro principio distributivo. El propio RAWLS anota que ese principio está inspirado en una concepción de la equidad de acuerdo con la cual la mejor forma de dividir un pastel es exigir que quien lo parta tome la última tajada ${ }^{11}$. Si suponemos el autointerés racional, la persona dividirá el pastel igualitariamente para maximizar el tamaño de su tajada. Para establecer el carácter deseable de una división igual, nada aporta que, en gracia de discusión, concedamos las suposiciones. Si supiéramos, por ejemplo, que uno de los receptores no había comido en tres días, que otro tenía tres pasteles en su bolso, y que uno tercero era un diabético que se enfermaría si comiera pastel, entonces se evaporaría rápidamente cualquier atractivo intuitivo de la regla según la cual «quien parte toma la última tajada». La regla del que parte el pastel sólo parece llamativa a la luz de un compromiso previo con la igualdad. Lo que ofrece es un camino para que el autointerés lleve a las personas allí; nada menos, nada más.

Lo mismo sucede con el argumento de que las personas respaldarían una presunción igualitaria tras el velo de ignorancia. RAWLS estructura explícitamente la situación de elección para producir este resultado, por lo cual aquella no puede proporcionar un argumento a favor del carácter deseable del resultado. Si RAWLS les hubiera pedido que hicieran otras suposiciones tras el velo de ignorancia, sin duda las personas podrían haber sido inducidas a escoger un principio distinto. Por ejemplo, como lo anotó HARSANYI en una crítica temprana, si las personas tuvieran una mayor propensión al riesgo de la que RAWLS les asignó en la posición original, entonces sería más probable que ellas escogieran el utilitarismo sobre la concepción de justicia de RAWLS ${ }^{12}$. Si ha de existir una presunción a favor de la igualdad, a esta todavía le hace falta una justificación que sea independiente de un mecanismo expositivo que supone que el carácter deseable de la igualdad ya ha sido establecido.

\subsection{Arbitrariedad moral}

¿Qué argumento independiente ofrece RAWLS en pro de una presunción igualitaria? Una candidata es su tesis sobre la arbitrariedad moral, según la cual nuestras diferencias son accidentales desde un punto de vista moral, sean ellas producto de nuestra naturaleza o de nuestra crianza. RAWLS está en lo cierto al decir que los resultados distributivos que están moldeados por esas diferencias requieren una justificación.

10 Para el «velo de ignorancia», vid. RAWLs, Teoría, op. cit., 163-169. En la formulación final de sus principios, ibid., 82-87, RAWLS opta por el punto de vista de la persona más desaventajada como el punto de vista de la justicia, pero ello solo es así por la suposición de que si la persona afectada del modo más adverso por una política pública escogiera esa política, entonces también lo harían todas las demás personas. De esta forma, el punto de vista de la persona más desaventajada funciona como representación del punto de vista de todas las personas. Es posible cuestionar la verosimilitud de estas movidas; vid. I. SHAPIRO, Evolution of Rights in Liberal Theory, London, Cambridge University Press, 1986, 226-230 (citado en adelante como SHAPIRO, Evolution).

11 RaWls, Teoría, op. cit., 108.

12 J. HaRSANYI, «Can the Maxim in Principle Serve as a Basis for Morality? A Critique of John Rawls's Theory», American Political Science Review, núm. 69, 1975, 594. 
Su argumento sobre la arbitrariedad moral desafía de manera persuasiva cualquiera de las versiones de la tesis de que las pérdidas (o las ganancias) deberían permanecer allí donde caen ${ }^{13}$. De hecho, en otro lugar he argumentado que RAWLS no es lo suficientemente exhaustivo en su defensa de esta tesis. RAWLS fracasa en su intento de distinguir las capacidades, que dice estar distribuidas en formas moralmente arbitrarias, de las elecciones que las personas hacen sobre cómo usar esas capacidades, que no lo están. No hay ninguna buena razón para suponer que, desde un punto de vista moral, las diferencias en la capacidad de decidir utilizar las capacidades propias de manera más o menos efectiva son en algún modo menos arbitrarias de lo que lo son las diferencias en las capacidades en sí mismas ${ }^{14}$. Esta es, ciertamente, una conclusión desconcertante; ella amenaza con destruir por completo convicciones generalizadas sobre la propiedad y la responsabilidad personal. Pero ello no quiere decir que RAWLS nos provea razones convincentes para evitarla.

En la literatura desde RAWLS, el impulso por defender una presunción igualitaria ha estado animado por el rechazo de lo que G. A. CoHEN identificó en 1989 como «la derecha anti-igualitaria» ${ }^{15}$. La preocupación motivadora era que cualquier concepción de la distribución equitativa que ignorara la recompensa del esfuerzo y la ambición sería tan poco convincente que nadie le prestaría atención. En efecto, esta es una posibilidad real, salvo que puedan ponerse algunos límites a la arbitrariedad moral. Seguramente, fueron consideraciones de esta naturaleza las que motivaron el intento poco exitoso de RAWLS - que acabo de mencionar- de distinguir las capacidades de los usos que pueden dárseles. Consideraciones similares llevaron a R. DWORKIN a proponer una visión de la justicia distributiva que toma en cuenta la idea rawlsiana de arbitrariedad moral pero que es, no obstante, «sensible a la ambición». La visión de DWORKIN requiere una visión de la igualdad según la cual «las personas deciden qué tipo de vida van a llevar contando con información previa sobre el coste real que le imponen a otras personas con su elección y, por tanto, sobre las existencias totales de recursos que pueden usar de forma justa» ${ }^{16}$. DwORKIN intenta lograr esto al asignar «gustos y ambiciones» a la persona, y «poderes físicos y mentales» a sus «circunstancias», y al argumentar que aquellos, mas no estos, son irrelevantes para decidir la manera como deberían distribuirse los recursos ${ }^{17}$. De esta forma espera rescatar la idea de un agente responsable.

La estrategia de DwORKIN también falla. Las ambiciones que se nos ocurren desarrollar, tanto como los deseos que somos capaces de formar, están moldeados en gran medida — quizás incluso están determinados— por nuestros poderes y capacida-

13 RaWls, Teoría, op. cit., 30-31, 33-35, 105-106, 143-145, 639-645. En una de los primeras afirmaciones sistemáticas sobre el laissez-faire en el ámbito de la responsabilidad extracontractual por daños, O. W. HOLMES propuso la presunción básica de que las pérdidas deberían permanecer allí donde caen; O. W. HoLMES, «Lecture III», en O. W. Holmes, The Common Law, Cambridge, MA, Harvard University Press, 2009.

${ }^{14}$ I. SHAPIRO, «Justice and Workmanship in a Democracy», en I. SHAPIRO, Democracy's Place, Ithaca y London, Cornell University Press, 1996, 64-69; $73-75$ (citado en adelante como SHAPIRO, Democracy's Place).

15 G. A. COHEN, «On the Currency of Egalitarian Justice», Ethics, núm. 99, 933 (citado en adelante como COHEN, «Egalitarian Justice»).

16 R. DworkIn, «Igualdad de Recursos», capítulo 2 de R. Dworkin, Virtud soberana. La teoría y la práctica de la igualdad, traducido al castellano por F. Aguiar y M. ${ }^{a}$ J. BERTOMEU, Barcelona y Buenos Aires, Paidós, 2003, 80 (citado en adelante como DwORKIN).

${ }^{17} \mathrm{Ibid} ., 92$. 
des. Cuando describimos a una persona como ambiciosa, podemos estar describiendo algo básico de su psicología y constitución, pero ¿tenemos alguna buena razón para creer que ello no es producto ni de sus poderes físicos y mentales ni de su crianza o circunstancias de vida? «Pensar en grande», «decidir arriesgarlo todo», armarse de valor a través del auto-control para realizar actos exigentes ¿reflejan estas opciones ambición o capacidad? Ciertamente hay circunstancias en las que diríamos que la falta de confianza es una incapacidad que impide la formación (no solo la consecución) de ambiciones particulares. Diferentes personas tienen capacidades diferentes para formar ambiciones diferentes, y desde el punto de vista de DwORKIN esas capacidades diferentes deben estar tan contaminadas en un sentido moral como cualesquiera otras capacidades. Al menos en parte, Donald Trump es capaz de desarrollar ambiciones de mayor alcance que, digamos, Homer Simpson debido a su suerte en la lotería genética y a las circunstancias de su crianza.

La idea de que formamos nuestras ambiciones de algún modo que es independiente de nuestros recursos y capacidades supone, de manera poco creíble, que podemos concebir las metas con independencia de nuestra comprensión de nuestras capacidades y circunstancias de vida. Esto debería ser evidente para cualquiera que intente realizar un experimento mental en el cual se le exige elegir sus ambiciones futuras mientras permanece ignorante de sus poderes, capacidades, y circunstancias. El mundo está plagado de lo que he descrito como «brechas de empatía» que, como resultado de las experiencias de vida, limitan las aspiraciones que las personas consideran concebibles, por no decir creíbles. Usted puede fácilmente imaginarse a sí mismo/a pasando por encima de un charco, quizás incluso nadando un ancho río. Pero ¿se le ocurrirá considerar las posibilidades que hay del otro lado de un gran océano? ${ }^{18}$.

Es posible plantear argumentos similares sobre las habilidades diferentes para formar (o abstenerse de formar) distintos tipos de gustos, sean ellos costosos, compulsivos, o ambas cosas. ¿Podemos decir de una persona alcohólica, cuya aflicción es tan severa que no puede siquiera formar el deseo de no ser un alcohólico, que la preferencia por el alcohol resulta de su gusto y no de su incapacidad? Creo que no ${ }^{19}$. Para todos los gustos adquiridos (no solo los costosos), la experiencia del gusto es por definición condicional al ejercicio de capacidades pertinentes. El gusto por la buena cerveza o incluso simplemente por la cerveza, el gusto por un tipo particular de música, o incluso por cualquier música, todos estos gustos sólo pueden ser desarrollados a través del ejercicio de capacidades relevantes No atribuiríamos el gusto por la música a una persona que ha nacido sorda, aunque podríamos decir de manera inteligible que dicha persona podría desear tener tal gusto. De igual manera sucedería con la cerveza en re-

18 Vid. I. SHAPIRO, El estado de la teoría democrática, traducido al castellano por J. DE JÓDAR, Barcelona, Ediciones Bellaterra, 2005, 180-194 (citado en adelante como SHAPIRO, Estado).

${ }_{19}$ DwORKIN es parcialmente consciente de esta dificultad. Él toma en consideración un caso en el cual una persona tiene una obsesión incapacitante que le gustaría no tener. DwORKIN lidia con ello diciendo que tales ansias deberían entenderse como discapacidades y por tanto deberían ser manejadas a través de un esquema hipotético de seguros. DwORKIN nos pide especular sobre si, ex ante, personas con una cantidad finita de recursos para gastar en un seguro se habrían asegurado contra terminar teniendo la discapacidad en cuestión; vid. Dworkin, op. cit., 75-81. He indicado las dificultades de este esquema en SHAPIRO, Democracy's Place, op. cit., 70-71. Esto es, en todo caso, irrelevante para el punto que se está defendiendo aquí, que consiste en que la obsesión puede en sí misma incapacitar a una persona para formar el deseo relevante de segundo orden de hacer que la solución de DwORKIN del seguro hipotético funcione. 
lación con alguien que carece de papilas gustativas funcionales, o del sentido del olfato. La intuición que motiva a DwORKIN en este tema es que las personas sólo deberían ser consideradas responsables de las elecciones que hacen durante su vida, no de las cosas sobre las cuales no tienen control. Una variante de esta tesis puede ser defendible, pero el tratamiento que hace DwORKIN de ella no es más persuasivo que el de RAWLS. El resultado es que DWORKIN no ha logrado, como COHEN alega, «hacerle al igualitarismo el importante favor de incorporar en su seno la idea más poderosa que existe en el arsenal de la derecha anti-igualitaria: la idea de la elección y la responsabilidad» ${ }^{20}$.

El propio COHEN intenta lidiar con este problema, pero no con mayor éxito que DWORKIN o RAWLS. Cohen intenta reducir el problema al insistir en que no deberíamos confundir el argumento válido de que nuestras capacidades para el esfuerzo están «influenciadas» por factores más allá de nuestro control con el argumento falso, que personas como NOZICK atribuyen de manera equivocada a igualitaristas como RAWLS, de que esas capacidades están «determinadas» por factores más allá de nuestro control. Apuntar a esta distinción le permite a COHEN decir que, aunque no todo esfuerzo merece recompensa, hay algún esfuerzo que sí merece recompensa, de forma tal que el esfuerzo es en parte loable y en parte no, aunque COHEN concede que, en la práctica, «no podemos separar las partes» ${ }^{21}$.

En la medida en que este es un problema práctico, se trata de un problema devastadoramente grande, dado que el tema en cuestión es si y hasta qué punto el estado debería promover la redistribución u otra acción remedial para compensar las diferencias en los resultados que surgen de estas partes que son inseparables en la práctica. Pero en cualquier caso es engañoso decir que se trata de un problema únicamente práctico. Una vez concedemos que la propia decisión de escoger dedicar esfuerzo a algo está influenciada por factores moralmente arbitrarios, resulta evidente que la dificultad se convierte en una dificultad de principio y no en un tema práctico. Ciertamente COHEN no ofrece ninguna explicación sobre cómo aquel componente del esfuerzo que merece recompensa podría, en principio, ser identificado.

RAWLS, DWORKIN y COHEN escriben como si el argumento de la arbitrariedad moral generase una presunción igualitaria que sería tan radical que nadie podría tomársela en serio a menos que de alguna manera se le pudieran poner algunos límites. Ellos piensan que esto es esencial para rescatar la idea de que las personas deberían ser consideradas responsables de las elecciones que hacen, de forma tal que pueda decirse con justicia que merecen los beneficios o costos resultantes. Sin embargo, como acabo de anotarlo, los intentos en curso por articular los límites en cuestión fracasan porque el bozal de la arbitrariedad moral silencia las nociones de elección y responsabilidad, si es que logra silenciar algo.

Pero RAWLS, DWORKIN y COHEN no logran apreciar que no es necesario rescatar las ideas de libre elección y responsabilidad con el fin de salvar una presunción igualitaria debidamente disciplinada, si se considera que esa presunción está basada en el

${ }^{20}$ COHEN, «Egalitarian Justice», op. cit., 933 (versión en castellano de la traductora de este artículo).

21 Vid. NozicK, op. cit.; G. A. CoHEN, «Equality of What? On Welfare, Goods, and Capabilities», en M. Nussbaum y A. SEN (eds.), The Quality of Life, Oxford, Oxford University Press, 1993, 14-15 (versión en castellano de la traductora de este artículo). 
argumento de la arbitrariedad moral de RAWLS. Esto es así por la simple razón de que el argumento de la arbitrariedad moral de RAWLS, aunque válido, no genera una presunción distributiva de ningún tipo. Sin duda, las diferencias en nuestras ambiciones, gustos y deseos dependen de manera vital de fuerzas que están más allá de nuestro control; como tal, son moralmente arbitrarias por la misma razón que las diferencias en nuestras capacidades y circunstancias son moralmente arbitrarias. Todas esas diferencias requieren una justificación. Pero lo mismo sucede con las similitudes en nuestras ambiciones, gustos, y deseos. Estas son moralmente arbitrarias por la misma razón que las similitudes en nuestras circunstancias y capacidades son moralmente arbitrarias. Ellas, también, necesitan una justificación. Como lo dice S. HURLEY, «a priori, la razón para observar la diferencia de posición como un asunto de suerte no es más fuerte que la razón para concebir la igualdad de posición como un asunto de suerte: las personas pueden no ser responsables de ninguna de ellas» ${ }^{22}$. El argumento de la arbitrariedad moral de RAWLS no establece nada distinto de que cualquier arreglo distributivo requiere una justificación. No hay ningún punto de referencia presunto.

\subsection{La interpretación kantiana}

Quizás la candidata más convincente de RAWLS para una justificación independiente de su presunción igualitaria es la llamada interpretación kantiana de sus principios como expresiones procedimentales del imperativo categórico ${ }^{23}$. Pero un compromiso con la autonomía kantiana no implica la adopción de un régimen distributivo particular más de lo que lo hace el compromiso con la arbitrariedad moral. Sin duda podría mostrarse que la esclavitud está excluida por el mandato de nunca usar a las personas exclusivamente como medios de los fines propios, pero ninguno de los protagonistas de la literatura sobre justicia distributiva que conozco defiende el establecimiento de la esclavitud. En todo caso, el ejemplo de la esclavitud es instructivo aquí en la medida en que la objeción kantiana no se refiere a las dimensiones distributivas de la economía esclavista sino más bien a la negación de la humanidad de una persona al hacerla propiedad de otra. La objeción kantiana a la esclavitud quedaría en firme incluso ante argumentos que mostraran que los esclavos disfrutaban de beneficios distributivos que les hubiesen sido negados de otra manera. Incluso si fuese cierta, la fórmula según la cual «les damos a nuestros esclavos más de lo que ustedes pagan a sus trabajadores» no sería aceptada como una defensa de la esclavitud ${ }^{24}$ (un argumento similar podría hacerse en referencia a la fórmula de «separados pero iguales» del Apartheid y a otros

22 S. Hurley, «Luck and Equality», Proceedings of the Aristotelian Society, núm. 75, Suplemento, 2001, 56. HURLEY desarrolla el punto así: «[L] as consideraciones sobre la responsabilidad no nos dirigen a tomar la igualdad como la posición por defecto; tales consideraciones no especifican ni justifican hacerlo. La consecuencia inmediata de este punto es que per se la neutralización de la suerte no requiere que solamente neutralicemos un tipo de relación que es el resultado de la suerte y no otro... Las personas no son responsables de que haya cantidades iguales de maná, o de ningún otro tipo de cantidades particulares; las personas no son para nada responsables de ello», ibid., 56-57 (versión en castellano de la traductora de este artículo). Vid., en general, S. Hurley, Justice, Luck, and Knowledge, Cambridge, MA, Harvard University Press, 2003, 146-180.

${ }^{23}$ RaWLS, Teoría, op. cit., 293-294.

${ }_{24}$ R. W. FogeL ha expresado de manera elocuente por qué el argumento contra la esclavitud debería desprenderse de argumentos sobre sus beneficios económicos en Without Consent or Contract: The Rise and Fall of American Slavery, New York, Norton, 1994, 388-417. 
estatus deshumanizantes semejantes. Con frecuencia estos estatus vienen acompañados de injusticias distributivas, pero es la deshumanización, no la injusticia, lo que los hace cuestionables).

Al considerar la interpretación kantiana de los principios de justicia de RAWLS, deberían distinguirse dos objeciones diferentes. La menos fundamental consiste en observar que, si nuestra meta fuese hacer lo mejor posible por preservar la autonomía de todas las personas (y suponiendo que pudiésemos hacer operativa esa aspiración de una manera inteligible), la identificación de lo que sería necesario para lograrlo es un asunto que debería recaer en los economistas políticos y en los estudiosos de la política pública. Determinar la cantidad de redistribución que se requiere para lograr eficazmente la meta de la igualdad, si es que hay alguna cantidad tal que pueda lograrlo, depende de consideraciones complejas sobre la efectividad y los costes de diferentes instrumentos redistributivos, sobre los efectos que la redistribución tendría en los incentivos para el crecimiento, y sobre las relaciones entre el tamaño del pastel económico y los beneficios que se derraman hacia los menos aventajados. Cuando RAWLS declara que su teoría es agnóstica entre el capitalismo y el socialismo parece inclinarse en esta dirección ${ }^{25}$.

Pero una objeción más profunda asoma su cabeza cuando empezamos a preguntarnos si preservar la autonomía de todas las personas es algo siquiera inteligible en tanto que idea distributiva. La transición del universalismo kantiano a una presunción igualitaria debe implicar alguna versión del argumento según el cual estamos obligados a respetar la autonomía de todas las personas en condiciones de igualdad. Pero ¿qué puede significar esto cuando el mandato que buscamos obedecer supone que deberíamos conceder (como lo hizo KANT de manera realista) que las personas se usan constantemente las unas a las otras como medios, y simplemente nos instruye a no usarnos exclusivamente como medios para nuestros propios fines? Es difícil ver cómo esto puede tener alguna dimensión distributiva. ¿Implica ello tratar a todas las personas con consideración? ¿Con la misma cantidad de consideración? ¿Qué podría significar tal mandato en realidad? El precepto de KANT parece más susceptible de generar aforismos de buena conducta y buenos modales ( $«$ No seas grosero!» «!No seas abusador!» «!No seas malvado injustificadamente!») que algún principio distributivo. La interpretación kantiana de los principios de RAWLS es simplemente insuficiente para generar una presunción igualitarista porque es insuficiente para generar cualquier presunción distributiva.

Pero ¿por qué deberíamos querer comprometernos con una presunción distributiva igualitaria? Hace más de un cuarto de siglo, M. WALZER señaló que lo que las personas consideran cuestionable no es tanto la desigualdad como tal sino los usos que ellas hacen de los recursos distribuidos de manera desigual. En particular, es cuando las personas usan los recursos bajo su control para dominar a otras personas que objetamos que tengan esos recursos. Lo que genera resentimiento es el uso de la riqueza

25 RaWLS, Teoría, op. cit., 311-312. KANT era bien consciente de esto, cuando insistía en que «el bienestar no tiene principio ni para el que lo recibe, ni para el que lo dispensa (uno lo entiende así, el otro asá), porque afecta a lo material en la voluntad, que es empírico y por tanto impropio para el carácter universal de una regla»; I. KANT, El conflicto de las Facultades, traducido al castellano por E. TABERNIG, Buenos Aires, Losada, 2004, 119-120. 
para corromper a un político o para «comprar» un lugar en la universidad para un chico que no lo merece ${ }^{26}$. La solución que ofrece WALZER frente a este problema, consistente en construir barreras entre las esferas en las cuales distintos bienes tienen una influencia dominante de manera apropiada, enfrenta dificultades, como lo anoto más adelante, en la parte 4.1. Pero ello no le resta fuerza a la elocuente intuición que subyace a esa solución, según la cual lo que es cuestionable es la dominación y no la desigualdad. Por el hecho de que argumento contra una presunción igualitarista, no debería creerse que formo parte del grupo de quienes sostienen que los argumentos de justicia deberían renunciar a las consideraciones distributivas. Como es bien sabido, MARX sostuvo que, para entender la dinámica de la explotación, debemos abandonar el campo de la distribución en favor de aquel de la producción ${ }^{27}$. Más recientemente, teóricas como I. M. YOUNG y N. FrASER han sugerido que el paradigma distributivo debería ceder paso a un enfoque basado en el reconocimiento y la dominación ${ }^{28}$. No tengo del todo claro qué significa el término «paradigma» en estos argumentos. Creo que las defensoras de estas perspectivas no están orientadas en la dirección correcta si lo que sostienen es que podemos razonar de manera fructífera sobre la justicia en ausencia de consideraciones distributivas, o incluso que, en ausencia de consideraciones distributivas, podemos razonar de manera fructífera sobre las dimensiones de la justicia a las cuales apuntan esas teóricas. En buena medida, la explotación marxista tiene que ver con la distribución del trabajo, el reconocimiento tiene que ver con la distribución del estatus, y la dominación tiene que ver con la distribución del poder. Más aún, como lo desarrollo más adelante en la parte 4.5, al analizar la perspectiva de Ph. PETTIT, hay muchos escenarios en los cuales alcanzar la no-dominación hace necesario atender a —e incluso redistribuir - los recursos materiales y de otro tipo. En lugar de concebir la no-dominación como una alternativa a la justicia distributiva, es mejor pensar en la no-dominación como la esencia de la justicia y reconocer que con frecuencia esta se encuentra íntimamente ligada a consideraciones distributivas. Pensar de otra manera nos lleva por el camino de victorias simbólicas que, en el mejor de los casos, oscurecen lo que la justicia requiere y que operan en contra de los propósitos de esta.

\section{4. ¿La igualdad como neutralidad?}

Otro candidato rawlsiano para defender la igualdad como idea fundante de la justicia se apoya en la idea de neutralidad. La teoría de RAWLS de la justicia como equidad requiere que el estado sea neutral frente a concepciones «permisibles» de la buena vida que compiten entre sí, y frente a las doctrinas comprehensivas que dan origen a tales concepciones. Para RAWLS, esto significa garantizar la oportunidad de buscar la realización de cualquiera de esas concepciones de la buena vida y prohibir que el gobierno favorezca alguna de esas concepciones en particular o que otorgue «mayor asistencia

26 M. WALZer, Las esferas de la justicia. Una defensa del pluralismo y la igualdad, traducido al castellano por H. Rubio, México, Fondo de Cultura Económica, 1993, 17-43 (citado en adelante como WALZER).

27 K. MARX, El capital, vol. 1, capítulos 4-7, México, Siglo XXI, Londres, 1996, 179-276.

28 I. M. Young, La justicia y la política de la diferencia, Valencia, Ediciones Cátedra, 2000, 31-114; N. FRASER, «¿De la redistribución al reconocimiento? Dilemas en tomo a la justicia en una época "postsocialista" , en N. FRASER, Iustitia Interrupta: Reflexiones críticas desde la posición «postsocialista», traducido al castellano por M. Holgín e I. Jaramillo, Bogotá, Siglo del Hombre Editores, 1997, capítulo I, 17-54. 
a quienes buscan realizarla». Por el contrario, esta perspectiva exhorta al Estado a que adopte lo que podríamos considerar una postura oficial de no adhesión (disestablished) frente a las concepciones permisibles de la buena vida. El Estado debería garantizar la libertad de buscar la realización de cualquiera de esas concepciones, pero no debería promover una - $\mathrm{O}$ algunas- por encima las demás ${ }^{29}$.

Esta postura puede parecer como un igualitarismo fundamental e inequívoco, dado que las protecciones y garantías de la no-adhesión están disponibles para todas las personas en condiciones de igualdad; pero en realidad esto no es así. Para comenzar, nótese que a RAWLS no lo perturban los efectos desiguales de su neutralidad institucional. RAWLS reconoce que el régimen que favorece tendría «efectos e influencias importantes sobre cuáles doctrinas comprehensivas perduran y obtienen adeptos con el pasar del tiempo», lo cual sería «fútil intentar contrarrestar» ${ }^{30}$. Más aún, la regla de neutralidad de RAWLS es anti-igualitaria en un sentido más inmediato que el que su admisión captura, ya que, bajo las restricciones de esa regla, las diferentes doctrinas comprehensivas que son permisibles no salen igualmente libradas. En el sentido más obvio, mientras que una persona que no es adepta a ninguna religión o cuya doctrina comprehensiva incluye la creencia de que la práctica religiosa no tiene ningún lugar en la arena pública obtiene exactamente lo que quiere del esquema de RAWLS, una persona que favorece la existencia de una iglesia oficial (sin mencionar la de una iglesia fundamentalista) no obtiene tal resultado. Después de todo, la defensa de la postura «neutral» de RAWLS frente a concepciones permisibles del bien nunca consiste en decir que a todas las personas les irá igual de bien, sino en decir que todas las personas disfrutarán de la mayor cantidad de libertad que es posible tener de un modo que sea consistente con la garantía de un libertad igual para todas las personas ${ }^{31}$. Una persona partidaria de una iglesia oficial tiene más libertad religiosa bajo el régimen de no-adhesión de la que tendría una persona no conformista bajo un régimen con una iglesia oficial, pero sigue siendo cierto que a aquella le va menos bien que a esta en el régimen de no-adhesión de RAWLS. Podemos admitir que hay un sentido residual en el cual este principio trata de igual forma a los partidarios de todas las doctrinas comprehensivas: a todos se les garantiza la máxima libertad religiosa que es compatible con una libertad igual para todos. Pero intente usted, si es que puede, vender tal cosa como tratamiento igualitario a quien favorece una religión oficial. Aquí la igualdad no está haciendo el trabajo polémico.

Una cuestión más importante es que la discusión precedente sólo lidia con la postura apropiada del estado frente a doctrinas comprehensivas y concepciones del bien que son permisibles. La discusión no se refiere a los propios procedimientos a través de los cuales RAWLS clasificó esas doctrinas y concepciones como permisibles o no permisibles. RAWLS es rotundo al afirmar que tal proceso de clasificación no es neutral en un sentido procedimental. Como se anotó anteriormente en la parte 2.1, los procedi-

29 Vid. J. RaWLS, «The Priority of Right and Ideas of the Good» (RAWLS, «Priority») en J. RaWLS, Collected Papers, S. FreEman (ed.), Cambridge, MA, Harvard University Press, 1999, 449, 457-461 (citado en adelante como RAWLs, Collected Papers); y RAWLs, Teoría, op. cit., 446-447. Es cierto que RAWLs invoca la idea de des-establecimiento en este contexto pero, por las razones que se desarrollan en el siguiente párrafo, me parece que esa idea captura la esencia de su argumento.

30 RAWLS, «Priority», ibid., 460 (versión en castellano de la traductora de este artículo).

31 RAWLs, Teoría, op. cit., 286, 340. 
mientos que ocurren tras el velo de ignorancia son manipulados de manera consciente para inducir al lector a adoptar la concepción de RAWLS de la justicia como equidad, incluyendo la teoría delgada del bien que impone los límites de permisibilidad a dicha concepción. En consecuencia, no es posible decir que los juicios sobre el carácter aceptable de las doctrinas comprehensivas y de las concepciones del bien resulten de un proceso neutral. En formulaciones posteriores, RAWLS continúa sosteniendo de manera rotunda que la justicia como equidad no puede garantizar «la igualdad de oportunidades para avanzar cualquier concepción del bien». Esa concepción de la justicia tan solo permite la realización de concepciones permisibles, definidas como «aquellas que respetan los principios de justicia» ${ }^{32}$. El RAWLS maduro apela a la neutralidad procedimental únicamente en el sentido de decir que esta expresa «una concepción política que apunta a ser el centro de un consenso superpuesto». Como es bien sabido, el consenso superpuesto «incluye todas las doctrinas filosóficas y religiosas que normalmente se desarrollan y ganan adeptos en una sociedad democrática constitucional más o menos justa» ${ }^{33}$. El consenso superpuesto «busca un terreno común $-\mathrm{o}$, si se prefiere, un terreno neutral, dado el hecho del pluralismo $\longrightarrow{ }^{34}$. Sea cual sea el significado de lo anterior, este no puede ser que el carácter justo del orden político depende de que la neutralidad sea expresada como un terreno común, puesto que la defensa de la neutralidad como terreno común consiste en que esta es (o se dice que es) compatible con un orden político justo. La defensa de la neutralidad procedimental no es en sí misma neutral en sentido procedimental. A fortiori esta no puede servir como sustituto para defender un compromiso fundacional con la igualdad ${ }^{35}$.

\section{LA DOMINACIÓN: UN TIPO PARTICULAR DE NO-LIBERTAD}

Si las desigualdades son cuestionables sólo en la medida en que facilitan la dominación, surge la pregunta de qué es la dominación. ¿Cómo saber que hay dominación cuando la vemos? ¿Y por qué debería importarnos su presencia? Responder estas pre-

\footnotetext{
${ }^{32}$ RAWLS, «Priority», op. cit., 459 (versión en castellano de la traductora de este artículo).

33 J. RAWLS, «Justicia como equidad: política, no metafísica», La Política: Revista de estudios sobre el Estado y la sociedad, núm. 1, 1996, 25 (citado en adelante como RAWLS, «Justicia como equidad»).

34 RAWLS, «Priority», op. cit., 459 (versión en castellano de la traductora de este artículo).

35 Una dificultad similar surge de la defensa que Ch. LARMORE hace de la neutralidad. LARMORE afirma que cuando dos personas están en desacuerdo sobre algo que constituye un obstáculo para lograr el acuerdo que están intentando alcanzar, ambas deberían prescindir de las creencias que la otra persona rechaza para ver si hay un terreno común neutral «con la esperanza o bien de resolver la disputa o bien de eludirla». LARMORE se refiere a esta «norma moral del igual respeto», como una regla neutra en el sentido de que es «compatible con un amplio rango de visiones de la buena vida sobre las cuales las personas están en desacuerdo»; vid. Ch. Larmore, Patterns of Moral Complexity, London, Cambridge University Press, 1987, 53, 65-66 (versión en castellano de la traductora de este artículo). Pero como lo nota J. FISHKIN, no hay razón alguna para creer que este principio de la neutralidad como terreno común arrojará conclusiones políticas particulares — dejando de lado aquellas que LARMORE dice que tiene - tales como la tolerancia religiosa o algo parecido al principio de diferencia de RAWLS; vid. J. FishKIN, reseña bibliográfica del libro Patterns of Moral Complexity escrito por Ch. LARmore, Political Theory, núm. 17, 1989, 153-156. Incluso si el principio arrojara conclusiones particulares, ello no equivaldría a una justificación del principio, como lo concede LARMORE en su respuesta a FISHKIN: «Aunque intento explicar el contenido de la norma del igual respeto, no ofrezco ninguna justificación de esta norma en sí. No tengo idea de cómo procedería una justificación tal...»; Ch. LARMORE, «Liberal Neutrality: A Reply to James Fishkin», Political Theory, núm. 17, 1989, 581 (versión en castellano de la traductora de este artículo).
} 
guntas requiere atender a las relaciones entre la no-dominación y la libertad. Si pensamos en la libertad como el summum bonum, como algunos teóricos nos proponen hacerlo, entonces la no-dominación tendría una relación similar con la libertad que la que acabo de argumentar tiene con la igualdad. La no-dominación sería un bien instrumental dirigido a la realización de la libertad. Yo quiero decir algo distinto. La nodominación se relaciona de manera más estrecha con la libertad que con la igualdad; de hecho, la no-dominación es una forma de libertad. Como resultado, la literatura sobre la libertad es, en efecto, relevante para entender las fuentes de la dominación y los modos de corregirla, como veremos a continuación. Pero la no-dominación amerita una delimitación independiente, con el fin de evitar que nos enfrasquemos en controversias que no requieren ser resueltas para ofrecer una justificación convincente de la no-dominación como piedra fundante de la justicia.

La no-dominación es un término negativo, definido como la antítesis de la dominación. Más adelante diré algo más sobre su carácter negativo y reactivo. Aquí me centro en las restricciones particulares a la libertad a las que se dirige. Es decir, antes de enfocarnos en la no-dominación deberíamos decir algo sobre la dominación. Hay cuatro características de la dominación que ameritan particular atención.

La dominación es, en primer lugar, un tipo de no-libertad que involucra un elemento humano significativo. Un abismo natural o una condición médica pueden limitar nuestra libertad, pero no identificaríamos a ninguno de ellos como una fuente de dominación. Experimentamos la dominación cuando nuestra libertad se restringe porque estamos en poder de otros, sean ellos esclavistas, torturadores, esposos o empleadores. Con esto no quiero insistir en que la dominación resulta siempre de la agencia humana consciente. La dominación puede ser experimentada como subproducto de estructuras políticas, sociales y económicas. Tales estructuras no se reducen a la agencia humana, pero no podrían existir sin ella. Este elemento humano distingue a la dominación de otros tipos de no libertad, y significa que los llamados a eliminar las fuentes de la dominación están siempre dirigidas en algún sentido — por más atenuado que sea- a cambiar cosas que los seres humanos hacen.

La dominación es un tipo particular de no-libertad también en el sentido de que generalmente se considera que quienes son responsables de ella pueden alterarla. La libertad de un padre está restringida por el llanto de un niño, pero esto no constituye dominación porque el niño no tiene el poder de hacer nada al respecto. Cuando se acusa a una persona o un estado de cosas de ser responsable de dominación, se desencadena una presunción de que los agentes relevantes pueden comportarse de formas distintas que aliviarían esa dominación, al menos en principio. Las personas pueden, por supuesto, equivocarse en cuanto a lo que puede servir para aliviar la dominación; pueden atribuir su impotencia al rencor de un dios furioso que sólo puede aplacar su ira a través del sacrificio humano. O pueden identificar correctamente el odio étnico como la fuente de su opresión y tener razón en que, en principio, esta podría ser eliminada; sin embargo, es posible que nadie sepa cómo lograr esto en la práctica. La descripción de la no-libertad como dominación alude a la posibilidad de su eliminación; la realización de esa posibilidad es otro asunto.

Esto no quiere decir que todas las fuentes de dominación en el mundo pueden ser restringidas. Limitar el poder de los banqueros de inversión puede implicar aumen- 
tar aquel de las agencias oficiales de regulación, y es una cuestión empírica definir si los reguladores son más o menos propensos que los banqueros a ejercer dominación. FOUCAULT puede haber estado en lo cierto en que eliminar un yugo que genera dominación normalmente genera nuevas posibilidades de dominación, pero es una pregunta abierta si ello sucede en todos los casos. Incluso si es así, algunos tipos de dominación serán más severos que otros, y algunos serán soportados por personas que son más vulnerables a sus efectos dañinos que otras. Cualquier teoría bien desarrollada de la no-dominación tendría que investigar estas diferencias. Mi visión del poder enfocada en los recursos tiene la intención de ser un paso en esa dirección.

La dominación es, en tercer lugar, un tipo de no libertad que lleva consigo el tufo de lo ilícito. Nuestra libertad es restringida con frecuencia cuando estamos bajo el poder de otros, pero esto no constituye dominación a menos que ese poder sea de alguna manera abusado o puesto forzosamente al servicio de un propósito ilegítimo. Los hijos están bajo el poder de sus padres, los estudiantes de sus profesores, los trabajadores de sus empleadores; en todos estos casos, su libertad está limitada. Pero sólo pensamos en ello como dominación si quienes tienen posiciones de autoridad abusan de su poder de alguna manera, como sucede cuando el empleador/a o profesor/a solicita los servicios sexuales de su subordinado/a como condición para darle un ascenso o una buena nota. Cuando las personas se acusan unas a otras de dominación, lo hacen para cuestionar la legitimidad de una relación de poder. Incluso las fantasías de dominación resaltan esto, al involucrar fetiches de mazmorras, esclavitud u otras formas de control ilícito. Cuando decimos que alguien es dominante, expresamos desdén; decir que alguien es poderoso no tiene necesariamente un sentido negativo. Las guerras de dominación no se consideran justas; mientras que las guerras para escapar a su yugo se consideran defendibles. Sin duda hay excepciones. Puede decirse que los equipos deportivos se dominan los unos a los otros sin que haya un prejuicio contra el dominador, y a veces los economistas dicen de manera neutra que una elección domina a otra, pero realmente estas son excepciones. La dominación, como tal, es rara vez defendida como algo deseable. Cuando lo es, como lo fue por NiETZCHE, ello en general se condena como una promoción amoral de un síndrome übermensch, o como algo peor ${ }^{36}$.

Esto inevitablemente plantea la pregunta: ¿quién identifica el carácter ilícito de la dominación, y cómo? Frente a este desafío, yo he adoptado un enfoque en dos frentes, que involucra una deferencia matizada al conocimiento contextual o a la sabiduría de sus participantes. La idea es estar de acuerdo, pero sólo hasta cierto punto, con A. MACINTYRE y M. WALZER en que los valores que guían las prácticas sociales de los seres humanos deberían ser definidos por los participantes a través de procedimientos que han evolucionado a través del tiempo como procedimientos apropiados para hacer

36 En cualquier caso, la defensa de NIETZCHE de la voluntad de poder es una teoría no del deseo de dominar a otros sino de comportarse con indiferencia frente a ellos. En efecto, NiETZSCHE culpaba al advenimiento de la democracia de la dominación política y social — tal como los castigos criminales bárbaros- que identificaba a su alrededor. NIETZCHE sentía desprecio por el individualismo de su época, pero ello era así porque lo veía como una perversión del individualismo romántico, marcado por la decidida búsqueda de la grandeza, que él atesoraba; F. NIETZSCHE, «The Genealogy of Morals», en The Birth of Treagedy and the Genealogy of Morals, traducido al inglés por F. GolfFing, New York, Anchor Books, 1956, 158-229 (puede consultarse la versión en castellano: Contribución a la genealogía de la moral, traducida al castellano por J. E. DE MUÑaGORRI, Madrid, Biblioteca Filosófica, 1929). 
esas elecciones ${ }^{37}$. Los participantes de un contexto particular dominan el conocimiento al nivel de la calle que es relevante para distinguir los usos lícitos de los usos ilícitos de la autoridad. Pero nuestra deferencia a esos participantes debería ser matizada porque los juicios externos pueden contribuir de manera apropiada allí donde hay intereses básicos en juego. Así, tiene sentido respetar los juicios de los padres sobre el tratamiento médico de sus hijos, pero no cuando el hijo de unos científicos cristianos morirá como resultado de que se le niegue una transfusión sanguínea. Tiene sentido ser deferentes a las prácticas gerenciales que han evolucionado dentro de compañías y universidades, pero no cuando ellas se convierten en cortinas de humo para cometer violaciones sexuales. Y tiene sentido exigir a los colegios que tengan en cuenta a los padres de familia en asuntos relativos a las convenciones sexuales, pero no cuando se trata de negar a los niños un conocimiento vital sobre las enfermedades de transmisión sexual. Si hay intereses básicos comprometidos o amenazados, lo correcto es que el estado se interese en el asunto, aun cuando la definición de lo que debería hacer depende de la gravedad de la amenaza a los intereses básicos y de la disponibilidad de instrumentos remediales que no creen formas de dominación más serias que aquellas que buscan prevenir ${ }^{38}$.

En cuarto lugar, cuando la gente habla de la dominación y la no-dominación, se invoca un tipo distintivo de particularismo que no necesariamente está presente cuando se habla de la libertad o de su ausencia a un nivel más general. Este particularismo está ligado al hecho de que la dominación está enraizada en los arreglos colectivos de los seres humanos. Si, en última instancia, la dominación ocurre siempre como resultado de las acciones o prácticas de otros, entonces cualquier acusación de dominación conduce naturalmente a preguntas mordaces sobre esas acciones o prácticas. ¿De quién son esas acciones o prácticas? ¿Qué son? ¿Cómo producen control, y por qué es este ilícito? Como veremos, esto significa que los argumentos sobre la dominación involucran reclamos relacionales que invariablemente se arraigan en lo específico. Tal vez las personas no son libres en algún sentido existencial, como sucedería si el determinismo fuese cierto, si fuésemos «existencia hacia la muerte», como dijo HEIDEGGER ${ }^{39}$, o por alguna otra razón no asociada a las relaciones humanas. Sin embargo, la dominación está enraizada en lo particular.

Una estrategia diferente, adoptada por Ph. PETTIT, consiste en tratar la no-dominación como el mecanismo político necesario para lograr el ideal filosófico de la igualdad. En la parte 4.5 tendré algo más que decir sobre los argumentos institucionales de PetTit. Aquí diré simplemente que tratar la no-dominación como el instrumento para alcanzar la igualdad, como lo hace PETTIT, no le da importancia suficiente a la no-dominación como un ideal normativo a título propio y no como un simple instrumento para lograr algún otro beneficio. Más aun, a mí me preocupa una defensa de la no-dominación que la haga depender de que primero creamos en una visión particular

37 A. MacInTyre, Tras la virtud, traducido al castellano por A. VALCÁRCEL, Barcelona, Crítica, 1987, 226-221; WALZER, op. cit., 17-34.

${ }^{38}$ En esto hay un paralelo con la métrica de la justicia de RAwLS en la medida en que él aboga por los juicios interpersonales sobre bienes primarios pero no por los usos que la gente hace de esos bienes en sus planes de vida; vid. SHAPIRO, Democratic Justice, op. cit., capítulos 2-3.

39 M. Heidegger, Ser y tiempo, traducido al castellano por J. E. RiverA, Santiago de Chile, Editorial Universitaria, 4. ${ }^{a}$ ed., 2005. 
y refutable de la liberad. PETTIT sostiene que la no-dominación es el mejor instrumento disponible para lograr su teoría de la libertad como «control discursivo». Algunos elementos de esta teoría de la libertad me parecen atractivos; otros me parecen problemáticos ${ }^{40}$. Creo que es un error que la justificación de la no-dominación sea mantenida como rehén de la resolución de estas cuestiones ${ }^{41}$.

M. WEBER sostenía que la existencia de la dominación requiere «la presencia actual de alguien mandando eficazmente a otro» ${ }^{42}$. Mi concepción es más amplia en cuanto creo que la dominación puede ocurrir (y con frecuencia ocurre) sin que haya órdenes explícitas que emanen de agentes identificables. La dominación puede resultar de acciones involuntarias e inconscientes como un subproducto de la distribución de recursos, y puede estar incrustada en relaciones estructurales. Sin embargo, mi concepción es más estrecha que la de WEBER en cuanto yo considero que la dominación sólo emerge del ejercicio ilícito del poder. Con frecuencia se exige obediencia en ejércitos, compañías, equipos deportivos, familias, escuelas y una cantidad incontable de otras instituciones, pero esa obediencia no es dominación salvo que se la utilice en pos de un propósito ilegítimo. En suma, mi concepción de la dominación difiere de otros tipos de no-libertad en cuanto centra la atención en fuentes humanas particulares y alterables de control ilícito. De esa manera se evitan las dificultades inherentes a los compromisos generalizados con la libertad o con la igualdad. Como resultado, creo que el ideal de no-dominación ofrece un fundamento superior para el análisis y los argumentos políticos. La no-dominación puede apelar a las personas que creen que la libertad y la igualdad son los bienes supremos porque captura mucho de lo que motiva a esas personas a valorar tales ideales en primera instancia (yo considero que esto es un plus). Podemos concebir la no-dominación como parte del consenso superpuesto o del acuerdo no completamente teorizado entre los liberales, que valoran la libertad, y los igualitaristas, que valoran la igualdad ${ }^{43}$.

\section{CONCEPCIONES DE LA NO-DOMINACIÓN}

La discusión precedente sugiere que la no-dominación debería preferirse como compromiso político fundacional por sobre la libertad o la igualdad, pero no nos dice todo lo que debemos saber sobre la no-dominación. En décadas recientes varios co-

40 En particular, soy receloso de toda concepción de la libertad que requiera un compromiso previo con el acuerdo y con metas compartidas. Ph. PetTit, A Theory of Freedom, London, Oxford University Press, 2001, 67 y ss. (la traducción al castellano es: Ph. PetTit, Una teoría de la libertad, Madrid, Losada, 2006); vid. también PetTit, Republicanismo. Una teoría sobre la libertad y el gobierno, traducido al castellano por T. DoMENECH, Barcelona, Paidós, 1999 (citado en adelante como PETTIT, Republicanismo), discutido más adelante, en la parte 4.5 .

${ }_{41}$ Siendo justos con PetTit, él no niega que puede haber defensas de la no-dominación distintas de la que él ofrece. Después de todo, su argumento es en primera instancia una teoría de la libertad, no de la no-dominación, así que uno podría interpretar que lo que dice PETTIT es que adoptar su justificación de la libertad como control discursivo es suficiente, más no necesario, para justificar la no-dominación tal como él la entiende.

${ }^{42}$ M. WeBER, Economía y sociedad. Esbozo de sociología comprensiva, traducido al castellano por J. MEdina Echavarría, J. Roura Parella, E. Ímaz, E. García Máynez y J. Ferrater Mora, México, Fondo de Cultura Económica, 1964, 43 (cursivas en el original).

43 Vid. RAwLS, «Justicia como equidad», op. cit.; Cass R. SunSTEIN, «Incompletely Theorized Agreements», Harvard Law Review, núm. 108, 1995, 1733. 
mentaristas han aceptado la idea, pero le han dado significados distintos. Además de WALZER, también han apelado al ideal de no-dominación en sus argumentos políticos J. Habermas, M. Foucault, Q. Skinner y Ph. PetTit. Cada una de sus visiones tiene algo digno de elogio, pero exhibe también limitaciones que, como explico, se combinan para sugerir la conveniencia de adoptar mi justificación alternativa de la no-dominación.

\subsection{Habermas}

A HABERMAS se lo conoce bien por basar su versión de la política democrática, junto con la idea prescriptiva de legitimidad que le sirve de guía, en aquello sobre lo cual se pondrían de acuerdo las personas en ausencia de coerción ${ }^{44}$. La manera precisa en la cual HABERMAS define la noción de acuerdo no coercitivo ha evolucionado a lo largo del tiempo, desde versiones tempranas de una «situación ideal del habla» a sus textos más recientes sobre derecho y democracia ${ }^{45}$. La noción de un acuerdo racional no coercitivo atraviesa sus diferentes formulaciones. HABERMAS quiere especificar los procedimientos y las restricciones que permitirían a las personas alcanzar un acuerdo genuino, lo cual significa que ellas no sufrirían ni de la confusión causada por la superstición o la ideología, ni de la intimidación resultante de las exigencias de la subordinación. Las personas serían persuadidas por el mejor argumento porque se trata del mejor argumento. De algún modo, la versión de HABERMAS es menos ambiciosa que la de RAWLS: HABERMAS no especifica cuáles son las instituciones o los arreglos distributivos que él cree que serían seleccionados bajo sus condiciones ideales. En su versión, estos no son asuntos para la filosofía de butaca, sino que resultarían de las deliberaciones no coercitivas que las personas llevarían a cabo. Esto hace a HABERMAS inmune a las dificultades que RAWLS enfrenta al intentar establecer que las instituciones que él favorece serían elegidas en la posición original o apoyadas por su consenso superpuesto ${ }^{46}$. Sin embargo, la posición de HABERMAS es más exigente que la de RAWLS en el sentido de que en su teoría, tal y como ha evolucionado, no hay nada semejante al giro «político, no metafísico» de RAWLS. HABERMAS, que en el fondo es un kantiano iluminista, espera que las personas no sólo puedan ponerse de acuerdo sobre las respuestas correctas a preguntas normativas sobre la política, sino también que, si deliberan de manera apropiada y con buena fe, puedan igualmente ponerse de acuerdo sobre por qué son esas las respuestas correctas. En efecto, sin este acuerdo de segundo orden, su deliberación no puede ser considerada auténtica. Y mientras que, a diferencia de RAWLS, HABERMAS no excluye que los argumentos tengan motivaciones religiosas y sectarias de otro

${ }^{44}$ Para todas las intenciones y propósitos, el uso que hace HABERMAS del término «legitimidad» es equivalente a lo que yo quiero decir con «justicia».

${ }^{45}$ Sobre la situación ideal de habla, vid. J. HABERMAS, «Wahrheitstheorien», en H. FAHRENBACH (ed.), Wirklichkeit und Reflexion, Pfüllingen, Neske, 1973, 211; y, «Reflections on the Linguistic Foundations of Sociology», en J. HABERMAS, On the Pragmatics of Social Interaction, Cambridge, MA, MIT Press, 2001, 1. Para formulaciones posteriores, vid. J. HABERMAS, Facticidad y validez. Sobre el derecho y el Estado democrático de derecho en términos de teoría del discurso, traducido al castellano por M. JiMÉNEZ REDONDO, Madrid, Trotta, 1998, 4. ${ }^{a}$ ed.; J. HABERMAS, «Corrección normativa versus verdad. El sentido de la validez deontológica de los juicios y normas morales», en J. HABERMAS, Verdad y justificación. Ensayos filosóficos, traducido al castellano por P. FABRA y L. DíEZ, Madrid, Trotta, 2002, 261.

46 Vid. SHAPIRO, Los fundamentos morales de la política, traducido al castellano por I. RoFFe, México, El Colegio de México, 2007, 147-187. 
tipo, sí espera que las personas se pongan de acuerdo en que solo las razones seculares serán aceptadas como razones elocuentes en escenarios deliberativos formales tales como los debates parlamentarios o los procesos legislativos ${ }^{47}$. La ética del discurso de HABERMAS no se conforma con meras coaliciones tácticas ni con ningún tipo de modus vivendi. Su ideal es el acuerdo deliberativo en la arena pública, modelado sobre la base de su visión del tipo de intelligentsia comprometida que él cree existió en la Europa del siglo XIX, pero que en su opinión se vio afectada por la evolución posterior de las economías, sociedades y formas de gobierno modernas ${ }^{48}$.

En ocasiones, los defensores de HABERMAS hacen énfasis en que sus teorías de la situación ideal de habla y de la ética comunicativa no tienen el propósito de describir escenarios deliberativos reales; simplemente expresan un ideal regulativo que está diseñado para ayudarnos a razonar sobre las restricciones y precondiciones apropiadas para la política democrática ${ }^{49}$. Quizás sea así, pero su ideal regulativo reposa al menos en dos suposiciones extravagantemente exigentes. La primera es que, en el fondo, todas las personas son kantianas; que todo el mundo puede ser llevado a aceptar que sólo las visiones que pueden traducirse a un lenguaje secular convincente pueden tener una influencia legítima en el debate político público. Dado que no hay ninguna buena razón empírica para creer esto, la posición de HABERMAS equivale a privilegiar de manera unilateral las visiones seculares universales, lo cual constituye un tipo de extralimitación racionalista que supone lo que HABERMAS debería demostrar. Esto puede simpatizarle a quienes ya están de acuerdo con HABERMAS, pero es poco probable que persuada a los que más requieren ser persuadidos ${ }^{50}$. Imagínese intentar convencer a un fundamentalista religioso de que no es tendencioso exigir que sus visiones religiosas sean defendibles e un lenguaje secular para que puedan jugar un rol en la política. El objetivo de limitar la dominación no debería ser rehén de la posibilidad de que las mentes pueden en principio encontrarse, por más especulativa que ella sea.

La segunda suposición extravagante es que es posible establecer un conjunto de restricciones que harían desvanecer del debate político las amenazas de poder y coerción. Esto es necesario para que la empresa de HABERMAS despegue porque la deliberación en escenarios cargados de poder es inherentemente sospechosa. Incluso si, suponiendo lo imposible, pudiesen diseñarse procedimientos para alcanzar este resultado, no es claro lo que se habría demostrado. La empresa habermasiana consiste en poner como precondiciones de la política democrática las propias cuestiones que generan la necesidad de esas precondiciones. Es justamente porque el poder es endémico a la

47 J. HABERMAS, «La religión en la esfera pública. Los presupuestos cognitivos para el "uso público de la razón” de los ciudadanos religiosos y seculares», traducido al castellano por F. J. GIL MARTíN, en J. HABERMAS, Entre naturalismo y religión, Barcelona, Paidós, 2006, 121; J. HABERMAS, «Lo político: el sentido racional de una cuestionable herencia de la teología política», en E. MENDIETA y J. VAN ANTWERPEN (eds.), El poder de

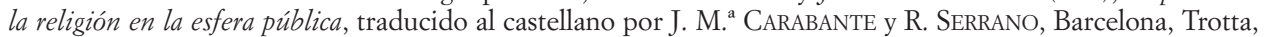
$2011,23$.

48 J. Habermas, Historia y crítica de la opinión pública. La transformación estructural de la vida pública, traducido al castellano por A. DOMENECH, Barcelona, Gustavo Gili, 1994, 4. ${ }^{\text {e ed. }}$

49 Vid. K. Olson, «Deliberative Democracy», en B. Fultner (ed.), Jürgen Habermas: Key Concepts, Durham, NC, Acumen Press, 2011, 140.

50 Vid. M. COOKE, «Violating Neutrality? Religious Validity Claims and Democratic Legitimacy», en C. Calhoun, E. Mendieta y J. van Antwerpet (eds.), Habermas and Religion, Cambridge, UK, Polity Press (en prensa, 2012). 
interacción humana que surge el imperativo de manejar las relaciones de poder con el fin de que la posibilidad de dominación sea mitigada cuando no se la puede evadir. Pero para que sea útil, ese imperativo debe basarse en una comprensión de la manera como el poder opera en la realidad, no en una serie de especulaciones sobre cómo sería el mundo si no existiera el poder ${ }^{51}$. La estrategia habermasiana ignora la realidad que motiva este proyecto, esto es, que las relaciones de poder son endémicas a la interacción humana. Sin las relaciones de poder, la política democrática sería innecesaria.

\subsection{FoucAulT}

La visión de la dominación de FOUCAULT es más atractiva que la de HABERMAS porque se basa en el reconocimiento de que el poder no puede ser erradicado. En una serie de historias de las relaciones sociales que van desde la vida familiar hasta la sexualidad, la demencia, el encarcelamiento y otras formas de control social, FOUCAULT ha expuesto el oscuro punto débil de la Ilustración ${ }^{52}$. FOUCAULT ofrece ejemplos fascinantes de las formas en las cuales la coerción desnuda fue desplazada por mecanismos más sutiles de control, que con frecuencia se hacen pasar por instrumentos de liberación. Por más convincentes que sean sus historias, desde el punto de vista que esgrimo aquí, la perspectiva de FOUCAULT se queda corta de tres maneras.

En primer lugar, es muy reduccionista. Soy lo suficientemente foucaultiano para creer que especular sobre lo que sería la política en ausencia de la dominación es una pérdida de tiempo, pero difiero de FOUCAULT pues pienso que en la interacción humana hay más que las relaciones de poder que la permean. Puesto de esta manera, es posible que FOUCAULT no hubiese estado en desacuerdo con mi argumento, pero nunca dijo nada que sugiriera que las dimensiones de poder de la interacción humana eran distinguibles de sus otras características de un modo importante. En el curso normal de los acontecimientos hay, sin duda, un ejercicio del poder en las aulas, las empresas, las familias, y las iglesias, pero en esos lugares suceden muchas otras cosas también: ilustración, producción, amor, veneración. Reducir esas actividades a las relaciones de poder que las permean pasa por alto el desafío básico que se plantea desde el punto de vista de la no-dominación, consistente en permitir, tanto como sea posible, que las personas lleven a cabo las actividades que le dan a la vida su significado y propósito, al tiempo que se limita el potencial de dominación que acompaña a tales actividades. Fue esto lo que me hizo desarrollar la noción de democracia como un bien condicionante

51 Vid., para una elaboración, SHAPIRO, Estado, op. cit., 56-58; vid. también A. AzMANOVA, The Scandal of Reason, New York. Columbia University Press, 2011, capítulo 2.

52 M. FOUCAUlT, La arqueología del saber, traducido al castellano por A. GARZÓn DEL CAMINO, Buenos Aires, Siglo XXI editores, 2002; M. FOUCAULT, El orden del discurso, traducido al castellano por A. GONZÁLEZ Troyano, Barcelona, Tusquets, 1992; M. Foucault, Historia de la locura en la época clásica, traducido al castellano por J. J. Utrilla, México, Fondo de Cultura Económica, 1988; M. FouCAult, Vigilar y castigar: El nacimiento de la prisión, traducido al castellano por A. GARZÓN DEL CAMINO, México, Siglo XXI, 1976; M. Foucault, Historia de la sexualidad, traducido al castellano por U. GuIÑAzú, México y Madrid, Siglo XXI, 1998; J. HABERMAS, Problemas de legitimación en el capitalismo tardío, traducido al castellano por R. GARCÍA Cotarelo, Buenos Aires, Amorrortu, 1975; J. Habermas, Teoría de la acción comunicativa, t. I, traducido al castellano por M. JimÉnez Redondo, Madrid, Taurus, 1987; J. Habermas, «Tres modelos normativos de democracia», en La inclusión del otro: estudios de teoría política, traducido al castellano por J. C. VELASCO Arroyo y G. Vilar Roca, Barcelona, Paidós, 1999, 231-246. 
o subordinado, que se orienta a domesticar las dimensiones de poder de la interacción humana mientras que restringe lo menos posible los demás bienes que persiguen las personas.

Además, la perspectiva de FOUCAULT carece de las herramientas necesarias para distinguir los ejercicios lícitos e ilícitos del poder. El esfuerzo por conseguir los bienes que buscamos involucra inevitablemente un ejercicio de poder, cuando menos debido a lo mucho que la vida social humana se encuentra ordenada de manera jerárquica. Pero las jerarquías no son intrínsecamente cuestionables. Como anoté en la parte 2.3, lo que es cuestionable es el abuso de las jerarquías para propósitos ilícitos. Sin duda, con frecuencia será - y debería ser - objeto de disputa si una jerarquía está siendo abusada o no. Por eso yo abogo por que haya mecanismos que faciliten la posibilidad de controvertir, así como por una serie de cuestionamientos sobre las jerarquías que estén diseñados para sacar a la luz los usos ilícitos del poder y para prevenir que estos se deformen y conviertan en sistemas de dominación. Estos cuestionamientos se refieren al grado en el cual las jerarquías particulares son inevitables, eludibles, elegidas, aisladas, o se eliminan por sí solas ${ }^{53}$.

Un tercer problema concomitante es que el trabajo de FOUCAULT no logra diferencia entre distintos usos ilícitos del poder. Él no hace nada para ayudarnos a distinguir entre formas de dominación más y menos malignas. En contraste, en mi teoría la dominación que involucra los intereses básicos de las personas es peor que la que no lo hace. Un millonario puede estar en posición de dominar a una esposa que sabe que, debido a un acuerdo prenupcial, puede perder millones en caso de divorcio. Pero esto merece una atención menor que el caso de una esposa que en la eventualidad de un divorcio se enfrentara a la posibilidad de pobreza extrema si no se le garantizaran las necesidades básicas para sobrevivir. Ambas son relaciones de dominación, pero una es peor. Justamente porque la ubicuidad de las relaciones de poder hace que el potencial de dominación siempre esté presente, es relevante poder decidir cuáles son las relaciones de poder más importantes desde la perspectiva de la justicia. Mi teoría del poder enfocada en los recursos facilita que se hagan los juicios comparativos pertinentes.

\subsection{WALZER}

La visión de WALZER tiene el mérito de enfocarse en las formas en las cuales las personas utilizan los recursos bajo su control para dominarse las unas a las otras. Además, WALZER tiene razón en que el uso de los recursos que son relevantes para una esfera de actividad humana con el fin de ejercer influencia en otra esfera puede ser una fuente de dominación, ya que ello constituye con frecuencia una fuente de ilicitud. Sin embargo, aunque ofrece una buena justificación de la resistencia a este tipo de dominación, es sorprendente lo poco que tiene que decir sobre la forma en que esa resistencia puede hacerse efectiva - sobre cómo las fronteras entre esferas deberían mantenerse robustas-. WALZER tampoco tiene nada que decir acerca de la manera como deberían resolverse los desacuerdos relativos a cuáles son los bienes relevantes para las diferen-

53 Para una elaboración, vid. SHAPIRO, Democratic Justice, op. cit., capítulo 3. 
tes esferas ${ }^{54}$. En contraste, yo sostengo que todos los dominios de la interacción humana deberían estar sujetos a restricciones democráticas condicionantes. Estas varían con el tiempo y las circunstancias, pero siempre incluyen los mecanismos que permiten participar en la toma de decisiones sobre la naturaleza de los bienes en cuestión y los derechos de oposición que hacen posible intentar cambiar esas decisiones.

WALZER también se equivoca al pensar que la transgresión de las fronteras que describe es la única, o incluso la principal, fuente de dominación en el mundo. En una fecha tan reciente como los años cincuenta, en la mayoría de estados de los Estados Unidos, no existía tal cosa como la violación marital por presunción legal concluyente, y la doctrina de la inmunidad frente a las reclamaciones por daños entre esposos blindaba a los maridos de la responsabilidad por agresión y por otras formas de daños causados a sus mujeres. Tras décadas de oposición por parte del movimiento de mujeres, tanto la excepción de la violación marital como la inmunidad a la responsabilidad por daños entre esposos han sido abolidas, pero esto no fue para nada el resultado de aislar la esfera de la vida doméstica de las normas que estaban fuera de ella. Por el contrario, para la abolición de estas reglas fue necesario un ataque frontal a los valores que gobernaban la definición del matrimonio y una transgresión activa de las fronteras que protegían a la «integridad» de la familia de los valores igualitaristas que prevalecían fuera de ella ${ }^{55}$. Mi noción de la democracia como bien condicionante involucra cierto nivel de deferencia a los valores imperantes, pero sólo en la medida en que esto no vuelva a las personas vulnerables a la dominación al poner en riesgo sus intereses básicos. Ser vulnerable a alguien que puede violarte o agredirte con impunidad compromete tus valores básicos.

\subsection{SKINNER}

La aproximación de Q. SKINNER a la no-dominación emplea el lente de lo que él llama la concepción «neo-romana» o republicana de la libertad. En su visión, la concepción neo-romana captura la comprensión más adecuada de la tradición libertaria negativa, que SKINNER espera rescatar de las garras de HOBBES y sus sucesores. Aunque los hobbesianos pueden haber «ganado la batalla», SKINNER no está dispuesto a tirar la toalla y admitir el fracaso en la guerra más larga. Su proyecto consiste en defender de manera convincente la idea de que la tradición republicana ofrece una versión de la libertad negativa que es superior a la hobbesiana, una versión que apela a la idea de un estatus independiente marcado por la ausencia de dominación ${ }^{56}$.

Como lo anota SKINNER en Hobbes y la libertad republicana, aunque hay alguna variación en la manera como HOBBES definió la libertad en distintos escritos, en el Leviatán claramente parece operar con un prototipo de la visión negativa de la libertad.

${ }_{54}$ Para una elaboración, vid. I. SHAPIRO, Political Criticism, Berkeley, CA, University of California Press, 1990, capítulo 3.

55 Sobre las cambiantes leyes relativas a la violación marital en Estados Unidos, vid. D. E. H. RusselL, Rape in Marriage, 2. ${ }^{a}$ ed., Bloomington, IN, Indiana University Press, 1990; R. M. RYAN, «The Sex Right: A Legal History of the Marital Rape Exception», Law and Social Inquiry, núm. 20, 1995, 941.

56 Q. SKINNER, Hobbes y la libertad republicana, traducido al castellano por J. UDI, Bernal, Prometeo, 2010,172 . 
Al hablar de la libertad haciendo referencia a la ausencia de impedimentos externos, al describir la libertad del sujeto haciendo referencia al «silencio de la ley» y a «aquellas cosas que en la regulación de sus acciones ha predeterminado el soberano: por ejemplo, la libertad de comprar y vender y de hacer, entre sí, contratos de otro género; de escoger su propia residencia, su propio alimento, su propio género de vida, e instruir (sic) sus niños como crea conveniente, etc. $\gg^{57}$, claramente HOBBES parece estar pensando en que la libertad individual connota una zona de acción en la cual el individuo es dejado solo por el Estado para que haga lo que a bien tenga. A pesar de que su teoría pronto se convierte en un absolutismo anacrónico, según la lectura de SKINNER, HOBBES ganó la batalla histórica, al avanzar la visión libertaria negativa de la libertad.

He anotado en otro lugar que hay algo de razonable en esta versión ${ }^{58}$, pero SKINNER extrae las conclusiones morales y políticas equivocadas pues no logra apreciar lo que hay de problemático en la distinción entre la libertad negativa y la positiva. Con frecuencia se cree que la diferencia entre libertad negativa y positiva está basada en que, mientras que los libertarios negativos se enfocan principalmente en los impedimentos a la acción, los libertarios positivos se preocupan esencialmente por aquello que el agente está en condiciones de hacer. Escritores como ROUSSEAU y HEGEL son vistos como libertarios positivos porque conciben la libertad como un concepto de «ejercicio» y no como un concepto de «oportunidad», de acuerdo con el sentido que Ch. TAYLOR da a estos términos. Para los libertarios positivos, la libertad consiste en ejercitar las capacidades humanas para alcanzar el potencial que nos caracteriza, y no somos libres en la medida en que esta posibilidad esté atenuada o bloqueada por arreglos sociales perjudiciales ${ }^{59}$. Los libertarios positivos conectan generalmente la libertad individual con la participación en instituciones sociales y políticas, una participación a través de formas que lleven a las personas a realizar su potencial.

Desde los escritos de BERLIN, ha sido convencional criticar a los libertarios positivos sobre la base de que su doctrina supone de manera equivocada que podemos saber cuál es el potencial de las personas, de forma tal que podemos entonces diseñar arreglos colectivos para facilitar que ese potencial sea alcanzado ${ }^{60}$. El caso límite de esta dificultad está ejemplificado por el eslogan de ROUSSEAU de que la exigencia de obedecer la voluntad general puede implicar que una persona sea «obligada a ser libre» ${ }^{61}$. Si las personas son coaccionadas a llevar a cabo ciertos tipos de participación colectiva con el fin de alcanzar una meta o concepción particular de la buena vida, entonces es difícil ver en qué sentido relevante se puede decir que son libres. Como resultado, con frecuencia se considera que BERLIN y sus seguidores tienen razón al sostener que la concepción positiva de la libertad es incoherente.

57 Hobbes, Leviatán, traducción al castellano y prefacio de M. SÁnCHEZ SARTo, México, Fondo de Cultura Económica, 1998, 173-174, 179.

58 SHAPIRO, Evolution, op. cit., 39-40, 276-277.

59 Ch. TAYLOR, «What's Wrong with Negative Liberty», en A. RYAN (ed.), The Idea of Freedom, Oxford, Oxford University Press, 1979, 179 (la versión en castellano es: Ch. TAYLOR, «¿Cuál es el problema de la libertad negativa?», en Ch. TAYLOR, La libertad de los modernos, traducido al castellano por Ph. DE LARA, Buenos Aires-Madrid, Amorrortu, 2005).

60 I. BERLIN, «Dos conceptos de libertad», en I. BERLIN, Cuatro ensayos sobre la libertad, traducido al castellano por J. BAYÓN, Madrid, Alianza Universitaria, 1988, 187.

${ }^{61}$ J.-J. Rousseau, El contrato social, Valladolid, Maxtor, 2008, 32. 
En parte, SKINNER quiere acompañar a BERLIN, pues está de acuerdo en que la concepción positiva es problemática. Sin embargo, SKINNER cree que la concepción maquiavélica o neo-romana de la libertad que él defiende ha sido clasificada de manera equivocada como una concepción positiva por el hecho de requerir la participación activa de los ciudadanos — tanto en el ejército como en la vida cívica de la república-. Para SKINNER, el requisito de MAQUIAVELO de prestar un servicio cívico es instrumental a la libertad de los ciudadanos republicanos. Se trata de un requisito necesario para que puedan protegerse a sí mismos de la dominación externa proveniente de vecinos agresivos y de la dominación interna proveniente de las élites domésticas ávidas de poder. Como resultado, SKINNER se resiste a la sugerencia de que una concepción negativa de la libertad no pueda incluir las exigencias del servicio cívico, y sostiene que una concepción que los incluya es, en efecto, superior a la concepción hobbesiana negativa ${ }^{62}$. En esta versión, la libertad es la antítesis de la esclavitud; somos libres cuando somos seres independientes y los actos virtuosos del servicio público son necesarios para asegurar ese estatus. Como lo pone SKINNER, «de acuerdo con los teóricos republicanos, la libertad humana no sólo se ve suprimida por actos de interferencia, sino también —y más fundamentalmente- por la presencia de un poder arbitrario. La mera existencia de relaciones de dominación y dependencia en el seno de una asociación política nos rebajaría de la condición de liberi homines u "hombres libres" a la de esclavos»" ${ }^{63}$.

Resulta atractivo que SKINNER se enfoque en la dominación como la fuente relevante de la ausencia de libertad en la política. Pero al caer en la dicotomía de la libertad negativa/positiva con el fin de rescatar la visión negativa de las garras de HOBBES y sus sucesores, a SKINNER se le escapa lo que está en juego en el debate y lo que resulta más cuestionable de la versión hobbesiana de la libertad. En mi opinión, deberíamos estar de acuerdo con G. MACCALLUM en que el debate entre los libertarios negativos y positivo desvía la atención de lo que más importa en las discusiones sobre la libertad y la dominación, y perpetúa discusiones que no pueden ser resueltas porque los protagonistas de ambos lados tienen razón sobre el demérito de los argumentos de sus oponentes ${ }^{64}$.

MACCALLUM señala que cualquier afirmación sobre la libertad involucra como mínimo una referencia a los agentes, a las condiciones que restringen (o habilitan) y a la acción. Frente a cualquier uso del término libertad, siempre tiene sentido preguntar: ¿quién es libre, de qué restricción (o en razón de qué condición habilitante) y para realizar qué acción? Mi sugerencia es que refrendemos la versión de MACCALLUM pero la

62 Q. SKINNER, «La idea de libertad negativa: perspectivas filosóficas e históricas», en R. RORTY, J. B. SCHNEEWIND y Q. SKINNER (comps.), La filosofía en la historia. Ensayos de historiografía de la filosofía, Barcelona, Paidós, 1990, 240 (citado en adelante como SKINNER, «Libertad negativa»).

${ }_{63}$ SkINNER, Hobbes y la libertad republicana, op. cit., 169. Una concepción comparable nutre la imagen afirmada por J. G. A. POCOCK y otros, quienes ofrecen lecturas «humanistas cívicas» de las motivaciones de los revolucionarios norteamericanos; su concepción de libertad expresa el ideal del granjero propietario independiente; vid. J. G. A. POCOCK, El momento maquiaveliano, Madrid, Tecnos, 2002; vid. también G. WoOD, The Radicalism of the American Revolution, New York, AA Knopf, 1992; B. BAILYN, Los orígenes ideológicos de la Revolución americana, Buenos Aires, Paidós, 1972.

${ }^{64}$ G. MacCallum, Jr., «Negative and Positive Freedom», en P. Laslett, W. G. Runciman y Q. Skinner (eds.), Philosophy, Politics and Society, serie 4, Oxford, Basil Blackwell, 1972 (citado en adelante como MACCAllum); I. Shapiro, «Gross Concepts in Political Argument», en I. SHAPIRO, The Flight from Reality in the Human Sciences, Princeton, NJ, Princeton University Press, 2005, 152. 
modifiquemos para tener en cuenta que, cuando hablamos de libertad política, entra a colación un cuarto término relacionado con la legitimidad, que se refiere a la pregunta: ¿’por qué — en virtud de qué autoridad - es el agente libre? Mientras que en la descripción de MACCALLUM la libertad es una relación triádica que incluye a los agentes, las condiciones restrictivas (o habilitantes) y las acciones; yo complemento su versión al sugerir que la mejor manera de concebir la libertad política es como una relación de cuatro términos que incluye tanto estos tres términos como las condiciones que dotan de autoridad a la libertad ${ }^{65}$. Esta referencia a las condiciones que dotan de autoridad a la libertad es vital para mi teoría de la no-dominación, pues provee tanto la invitación a como la base para distinguir entre restricciones lícitas e ilícitas a la libertad o a los modos de ejercerla.

SKINNER sostiene que, pese a los argumentos en sentido contrario, la versión de MACCALLUM es en realidad una versión de la doctrina de la libertad negativa: «En la medida en que el análisis de MACCALLUM sugiere una comprensión negativa de la libertad como ausencia de restricciones a las opciones de los agentes (lo cual hace), esta ("que la única versión coherente que puede darse del concepto de libertad es negativa") también es la implicación de su versión y de aquellas que dependen de ella» ${ }^{66}$. Pero esta aserción pasa por alto el punto de MACCALLUM. Su argumento es que todas las versiones de la libertad contienen elementos tanto negativos como positivos, algunos de los cuales están usualmente implícitos; que los libertarios negativos se enfocan principalmente en las restricciones, mientras que los libertarios positivos se preocupan por las condiciones habilitantes.

Sin duda, MACCALLUM reconoce que todos los conceptos inteligibles de la libertad involucran alguna noción de restricciones o de ausencia de las mismas, pero hablar de la libertad como la ausencia de restricción o limitación no hace que una teoría se convierta en «negativa» por el simple hecho de que este elemento nunca podría equivaler a una teoría de la libertad. En la teoría de MACCALLUM, la propia oposición entre libertad negativa y positiva debería evitarse, pues las restricciones y las condiciones habilitantes pueden ser fácilmente re-descritas como unas y otras. En efecto, las discusiones entre los libertarios negativos y positivos son análogas a las discusiones sobre si un prisionero no es libre por la presencia de una puerta bajo llave o por la ausencia de una llave. Por tanto, en opinión de MACCALLUM, es engañoso pensar que el lenguaje negativo o positivo es indicativo de alguna diferencia conceptual relevante ${ }^{67}$.

La discusión que propone SKINNER en Hobbes y la libertad republicana se basa en una discusión previa que él hizo de las ideas de MACCALLum, y lo que dice sobre la libertad republicana deja en claro que SKINNER no ha apreciado la fuerza de la tesis de MACCALlum. Planteándolo en términos de mi versión modificada del esquema de MACCALlum, SKINNER se enfoca centralmente en el estatus independiente del agente; al hacerlo, reduce la libertad al primer y cuarto término de la relación, en la medida en que el estatus del agente como persona libre o como esclavo depende de la autoridad legítima prevaleciente. El hecho de que la teoría de SKINNER guarde silencio sobre el segundo y tercer término de la relación — las acciones realizadas y las restricciones (o

\footnotetext{
65 SHAPIRO, Evolution, op. cit., 14-19.

66 SKINNER, «Libertad negativa», op. cit., 231, nota 8.

67 MacCallum, op. cit., 182, nota 9.
} 
condiciones habilitantes) que impiden (o facilitan) su realización — hace evidente que se trata de una teoría parcial de la libertad.

¿Por qué es esto importante? La respuesta que motivó a MACCALLUM y que me motiva a mí es que lo que resulta trascendental en las discusiones sobre la libertad no es el vocabulario que se utiliza, sino más bien lo que las distintas personas realmente pueden o no hacer en el mundo. SKINNER está en lo cierto al decir que un esclavo no podría considerarse libre, incluso si se encontrara bajo la dominación de un esclavista que fuese benigno en términos comparativos y que le permitiera tener algunos recursos discrecionales y un margen de elección, ya que en todo caso el estatus de persona del esclavo se vería comprometido ${ }^{68}$. Sin embargo, como lo anoté en la parte 2.3, conceder el punto de SKINNER no resuelve mucho de lo que está en juego entre las diferentes visiones que se enfrentan en la actualidad, pues casi cualquier teoría política disponible condena la esclavitud. SKINNER podría responder a esto que su ideal neo-romano excluye también otros estatus serviles, tales como la servidumbre, el apartheid, el patriarcado, y los sistemas de castas. No tengo ningún problema en conceder este punto, pero continúo preguntándome si en realidad hay un protagonista serio del otro lado de la discusión, y en todo caso quién es.

Como es bien sabido, A. FRANCE se burló de «la majestueuse égalité des lois, qui interdit au riche comme au pauvre de coucher sous les ponts, de mendier dans les rues et de voler du pain» ${ }^{69}$. La eliminación de la subordinación formal es sin duda importante desde el punto de vista de la no-dominación, pues cuando estamos en presencia de jerarquías de estatus éstas invariablemente se convierten en el centro de la disputa; pero su eliminación rara vez es suficiente para socavar la dominación. Una persona con el estatus de ciudadano libre puede enfrentar obstáculos tan enormes para realizar una serie de acciones disfrutadas por otras personas de manera rutinaria, que no nos inclinaríamos a concebirla como una persona inmune a la dominación. En décadas recientes, muchas empresas han despedido empleados y luego los han recontratado para realizar los mismos trabajos que hacían antes pero como contratistas independientes con salarios inferiores y sin prestaciones sociales. Su estatus como personas independientes ha aumentado, pero sería difícil argumentar de manera convincente que son menos vulnerables a la dominación que antes.

Este es el punto de MACCALLUM: en lugar de intentar reducir la libertad a uno u otro de sus componentes relacionales, deberíamos adoptar su teoría anti-reduccionista. El esquema de MACCALLUM es en sí mismo formal y vacío, pues refleja lo que podemos describir como la gramática analítica de la libertad. La esperanza de MACCALLUM es que, si adoptamos su teoría, en lugar de continuar participando en debates interminables sobre los «tipos» de libertad, podríamos cambiar de tema y enfocarnos más bien en las condiciones del mundo real que moldean no sólo el estatus de los agentes sino también las acciones que ellos pueden aspirar a realizar y los recursos y restricciones que afectan tales aspiraciones. Desde esta perspectiva, la visión de la libertad negativa que emerge de HOBBES es sin duda censurable, pero su deficiencia no puede remediar-

\footnotetext{
${ }^{68}$ Esto no ofrece una analogía exacta con la teoría de HobBES, en la cual, aunque el sujeto depende del silencio del soberano para ser libre, este no es su dueño.

69 A. France, Le Lys Rouge, Paris, Calmann-Lévy, 1992 [1894], 118.
} 
se mediante su contraposición a una visión neo-romana que reduce los reclamos sobre la libertad a reclamos sobre el estatus de los agentes.

\subsection{PetTit}

La teoría de SKINNER se desarrolla a un nivel bastante abstracto si se la considera desde el punto de vista de los arreglos institucionales existentes en la vida real. La discusión que ofrece PETTIT en su libro Republicanismo. Una teoría sobre la libertad y el gobierno y en textos posteriores tiene la ventaja de involucrarse con los arreglos institucionales de manera más directa. Y hay mucho de lo que PETTIT dice que coincide con mis argumentos institucionales. Yo estoy de acuerdo con su aseveración de que, en general, el mejor camino para mitigar la dominación consiste en democratizar las relaciones de poder. De manera más concreta, estoy de acuerdo con su argumento de que esto implica no sólo una presunción en favor de la participación incluyente en la toma de decisiones que nos afectan, sino también una presunción de que las personas siempre deberían ser libres de oponerse [«disputar» («contestation») es la palabra que usa PETTIT] a las decisiones con las que no están de acuerdo, incluso cuando se ha llegado a esas decisiones a través de medios democráticos legítimos ${ }^{70}$. También estoy de acuerdo en que, con frecuencia, lo que resulta más importante para que alguien tenga poder sobre alguien es la capacidad de interferir, no tanto la interferencia que de hecho suceda; es esa capacidad de interferencia lo que requiere un manejo institucional que prevenga la dominación ${ }^{71}$.

A pesar de estos puntos de acuerdo, PetTit y yo tenemos desacuerdos sustanciales. Estos se derivan de que la discusión de PETTIT le pone sorprendentemente poca atención a la seriedad relativa de los diferentes tipos de dominación, de que su definición de dominación lo enceguece frente a las formas en las cuales el poder puede ser utilizado para debilitar la dominación tanto como para causarla, de que (en sentido inverso) su justificación de los movimientos sociales y las asociaciones cívicas subestima las formas en que estos pueden promover la dominación en lugar de debilitarla, y de que su teoría del estado democrático como el instrumento principal de resistencia a la dominación está, en realidad, restringida hasta el punto de la impotencia por su teoría republicana de las instituciones.

El primer conjunto de desacuerdos tiene raíz en la decisión de PetTit de definir la dominación exclusivamente en relación con la capacidad de interferencia arbitraria en las elecciones de otra persona, sin atender a la naturaleza o importancia de tales elecciones. Cuando comienza a analizarla, PETTiT hace una reverencia a la proposición según la cual «la dominación en algunas áreas será probablemente considerada más dañina que en otras; mejor ser dominado en actividades menos centrales, por

${ }^{70}$ No me queda del todo claro cuál es la base primordial de esta presunción en la teoría de PETTIT. En mi opinión, esta se deriva del hecho de que no hay una regla de decisión democrática perfecta lo cual implica que incluso los mejores procedimientos democráticos dejarán a algunas personas sintiéndose no sólo agraviadas sino legítimamente agraviadas.

71 PeтtiT sostiene que tener el poder de interferir arbitrariamente con alguien es en sí mismo dominación, mientras que yo digo que ello crea la posibilidad de que haya dominación. Como explico abajo, en parte esta diferencia da cuenta de la actitud esquizoide de PETTIT frente al Estado. 
ejemplo, que en actividades más centrales» ${ }^{72}$. Pero PETTIT nunca define la noción de centralidad y, como veremos, las consideraciones que se relacionan con esa noción no juegan ningún rol en sus recomendaciones institucionales. Él habla brevemente de qué tan «extendida» es la dominación, por lo cual entiende el número de asuntos sobre los cuales las personas tienen libertad de elegir; y habla con mayor amplitud sobre la «intensidad» de la dominación ${ }^{73}$. No es del todo claro qué quiere decir esto específicamente, pero tiene que ver con el grado en el cual quienes tienen poder pueden actuar con impunidad. Los tiranos absolutos ejercitan la dominación con mayor intensidad que los esposos maltratadores que calculan de manera oportunista que pueden contar con una aplicación laxa de las leyes contra el maltrato conyugal ${ }^{74}$. Pero ni el número de las elecciones ni la intensidad de la dominación se refieren a la importancia de la elección en cuestión, de la cual PETTIT no tiene prácticamente nada que decir.

Las implicaciones de esta omisión se vuelven claras en su discusión del igualitarismo. PETTIT distingue el igualitarismo «material» del igualitarismo «estructural». Por igualitarismo «estructural», entiende los «poderes» que «incluyen todos aquellos factores que pueden incidir en el tejido político, jurídico, financiero y social» ${ }^{75}$. PETTIT piensa que, con respecto a estas cosas, son importantes tanto la igualdad absoluta como la igualdad relativa porque el que una persona sea víctima potencial de dominación depende no sólo de sus propios poderes sino también de los poderes de otros. En sus palabras, «en el país de los ciegos, el tuerto es el rey» ${ }^{76}$. Dado que «el valor absoluto de la intensidad de no-dominación de que disfruta una persona esta en función del valor relativo a los poderes», en el proyecto de no-dominación de PETTiT es esencial atender a la «tasa de poder en el conjunto de la sociedad» ${ }^{77}$. Con respecto a estas tasas de poder, PetTit alega, en consecuencia, que aumentar la desigualdad es presuntamente una mala idea porque el aumento del poder relativo tiene lo que él llama una «productividad marginal decreciente», mientras que los pasos hacia la igualdad son deseables ${ }^{78}$.

Más allá de la plausibilidad de estos argumentos ${ }^{79}$, PetTit los distingue de su posición sobre las desigualdades «materiales», frente a las cuales no opera ninguna presunción igualitaria. La razón es que los intentos de imponer una redistribución

72 Pettit, Republicanismo, op. cit., 86.

73 Ibid., 153.

${ }^{74}$ Ibid., 84.

75 Ibid., 153.

76 Ibid., 153.

77 Ibid., 153

78 Ibid., 155.

79 Yo dudo que esos argumentos sean ciertos, al menos sin reservas muy sustanciales a lo que PeTTIT dice aquí. No es para nada obvio, por ejemplo, que los países que no tienen armas nucleares se volverían más seguros si uno de cada dos países las tuviera. Si Irán desarrolla armas nucleares, puede ser más probable que Israel lo ataque que si no lo hace, y la probabilidad del ataque no disminuiría con una tasa marginal decreciente en relación con el número de armas que crea. Es más probable que sea una función escalonada. Consideraciones similares son pertinentes para las relaciones entre individuos dentro de los países, donde las carreras de armas pueden ser contraproducentes para desactivar los conflictos potenciales. Como lo he argumentado en otro lugar, NozicK (op. cit.) puede haber supuesto de manera demasiado apresurada que el poder es un monopolio natural, pero sin duda estaba en lo cierto en que el poder exhibe algunas propiedades de un monopolio natural (vid. SHAPIRO, Real World, op. cit., 159-162). Yo sospecho que en algunas ocasiones la relación entre poder relativo y seguridad tiene forma de $\mathrm{U}$, y que se vuelve indescifrablemente compleja si vamos más allá del tipo de situaciones de dos jugadores que PetTit analiza acá (Pеттiт, Republicanismo, op. cit., 154-158) hacia inte- 
igualitaria pueden en sí mismos involucrar dominación por parte del Estado, y esto no es compensado por el mismo tipo de productividad marginal decreciente que funciona con respecto a los poderes. «El dinero que me permitirá a mí hacer algo, pobre como soy, les permitirá hacer a ustedes las mismas cosas» ${ }^{80}$. PETTIT admite que la utilidad derivada del dinero puede disminuir con la riqueza, «pero su capacidad de comprar cosas, y su consiguiente capacidad para aumentar el alcance de las opciones no-dominadas, no disminuirá». Como resultado, mientras que su proyecto de no-dominación está comprometido con el «igualitarismo estructural», este «no está esencialmente comprometido con ningún tipo de igualitarismo material» ${ }^{81}$.

Este enfoque miope en el número de elecciones ignora lo importantes que son las elecciones para la perspectiva que busca evitar la dominación, y también desconoce las formas en las cuales los recursos materiales son con frecuencia esenciales para resistir la dominación. La financiación del seguro de salud a través del sistema tributario reduce los costos de salida para quienes de otro modo tienen que obtener ese seguro de sus empleadores y esposos, y de esa manera limita su vulnerabilidad a ser dominados por las personas de quienes dependen. Por eso, en Democratic Justice, yo alego que, cuando el ingreso social (social wage) es bajo, desde el punto de vista de la no-dominación se justifica que haya controles democráticos exigentes de la vida doméstica y laboral, aunque también alego que el carácter intrusivo de los controles exigentes es poco atractivo, y por ende que es preferible un régimen de ingreso social alto con menos controles ${ }^{82}$. Usted tendrá menos poder sobre mí — y por ende menos capacidad de dominarmecuanto menos dependa de mis relaciones con usted mi habilidad para defender mis intereses básicos ${ }^{83}$. De hecho, en un punto PETTIT describe la no-dominación como un bien primario ${ }^{84}$. Por eso es raro que ignore sus nexos evidentes con los recursos materiales. LOCKE dice que «un hombre no puede ser más justo al hacer uso de la necesidad de otro para forzarlo a ser su vasallo» que lo que puede serlo «al ofrecerle muerte o esclavitud con una daga en su garganta» ${ }^{85}$. Si estamos de acuerdo con PETTIT, como creo que deberíamos estarlo, en que la capacidad de ejercer poder (más que el hecho de que este sea en efecto ejercido) es con frecuencia crucial para la dominación, entonces deberíamos resistir su intento de desterrar de la teoría de la no-dominación los recursos materiales necesarios para reivindicar los intereses básicos de las personas.

Un segundo desacuerdo entre nosotros consiste en que, mientras PETTIT insiste en que tener la capacidad de interferencia arbitraria en la vida de otros constituye

racciones entre jugadores múltiples que están involucrados en numerosas relaciones de poder superpuestas de carácter tanto bilateral como multilateral.

80 PetтIT, Republicanismo, ibid., 159.

${ }^{81}$ Ibid., 159-160.

82 Vid. SHAPIRO, Democratic Justice, op. cit., capítulos 5-6.

${ }^{83}$ Este visión del poder enfocada en los recursos pone a mi argumento directamente en el campo recursista de RAWLS, DwORKIN, SEN y otros, pero mi enfoque difiere del suyo en cuanto yo creo que los recursos necesarios para reivindicar intereses básicos deberían garantizarse a las personas no para permitirles alcanzar alguna concepción de bienestar o de la buena vida, sino más bien para protegerlas de la vulnerabilidad a la dominación por parte de otros.

${ }^{84}$ PetTIT, Republicanismo, op. cit., 125-127.

85 J. LOCKE, First Treatise of Government, en I. SHAPIRO (ed.), Two Treatises of Government and A Letter Cooncerning Toleration, Princeton, NJ, Yale University Press, 2003, 1, par. 42 (versión en castellano de la traductora de este artículo). 
dominación, en mi versión tener esa capacidad no constituye por sí sola dominación, sino que crea el potencial de dominación. Esta distinción puede sonar semántica, pero tiene consecuencias significativas. En el parque infantil, el niño matón puede tener la capacidad de golpear a cualquiera de los niños más pequeños, pero puede ser conocido ampliamente por golpear solo a los niños negros. ¿Ejerce ese niño dominación sobre los niños que no son negros? ${ }^{86}$. El senador Joseph McCarthy tenía la capacidad de interferir arbitrariamente en la vida de muchos estadounidenses, pero es posible que las personas de izquierda vivieran con temor de él de una forma que las demás personas no lo hacían. Decir que McCarthy dominaba a todos los estadounidenses con quienes podría haber interferido ignora este hecho, pues trivializa la situación de quienes tenían buenas razones para temerle a McCarthy. Hoy en día, Estados Unidos tiene la capacidad de interferir arbitrariamente en Cuba, México, Canadá y Fiji, pero tiene relaciones muy distintas con cada uno de esos países desde el punto de vista de la dominación. Cuba ha sufrido una interferencia coercitiva explícita durante décadas; México siente periódicamente la presión del «poder suave» estadounidense; Canadá está sujeta a la influencia de un aliado más poderoso pero en gran medida con ideas afines; y Fiji no está afectado por el poder estadounidense de ninguno de los modos que son relevantes para los otros tres países.

Más aun, la posición de PeTTit desvía la atención de las formas en las cuales la interferencia puede mitigar la dominación. En el parque infantil, el niño más fuerte bien puede ser un matón, pero en vez de ello también puede ser quien protege a los niños más débiles de los matones. Si esto es de conocimiento común, entonces el mero hecho de que el niño más fuerte tenga la inclinación de proteger a los niños más débiles puede disuadir al matón o envalentonar a los más débiles a resistirlo o denunciarlo. Cuando las fuerzas de Saddam Hussein invadieron Kuwait en 1990, el presidente de los Estados Unidos George H. W. Bush lideró una coalición de fuerzas para expulsarlo. Bush vio en ello una oportunidad para institucionalizar un nuevo orden mundial post-guerra fría, orientado a hacerle frente a la agresión internacional y a fomentar las expectativas y los incentivos para minimizarla en el futuro. Bush utilizó el poder estadounidense al servicio de esa meta. Ello implicó la creación de normas de autorización internacional y de participación regional en el esfuerzo de contención, que no iban más allá de lo que se necesitaba para bloquear la agresión de Saddam Hussein. En efecto, Bush detuvo al matón sin convertirse él mismo en un matón ${ }^{87}$. Desafortunadamente, doce años después su hijo socavó esas normas con su invasión unilateral de Irak para derrocar el régimen, una acción deshonesta del tipo que había buscado prevenir la política de su padre. La formulación de PETTIT es insensible a estas distinciones, y por ende también

86 Agradezco a R. TRUPIN por este ejemplo.

87 Con esto no quiero defender todo lo que hizo Bush sénior en Irak en 1991. En particular, su decisión de alentar el levantamiento shiita en el sur y luego abandonarlo fue como mínimo un trágico lapso de juicio que llevó a la matanza evitable de incontables miles de iraquíes; vid. «War in the Gulf: Bush Statement», The New York Times (16 febrero 1991), disponible en: bttp://www.nytimes.com/1991/02/16/world/war-gulf-bush-statement-excerpts-2-statements-bush-iraq-s-proposal-for-ending.html, y la conferencia de prensa de abril de 1991 en la cual Bush indicó que Estados Unidos no apoyaría a los rebeldes, Dian McDonald, archivo inalámbrico, 179249, «US Forces Won't Intervene in Iraq's Civil War» (4 abril 1991), disponible en bttp://webcache.googleusercontent.com/search?q=cache:?6Fik-lFWW34J:www.fas.org/news/iraq/1991/910404-179249.btm +US +F orces + Won't+Intervene + in + Iraq's+Civil + War. $\% 22+$ President + Bush + firmly + reiter ated + that + be + does $+n o t \varepsilon c$ $d=1 \varepsilon h l=e n \varepsilon c t=c l n k E g l=u s \varepsilon s o u r c e=w w w . g o o g l e . c o m$. 
a la importancia que tiene que la administración Obama haya decidido volver a la política del Bush mayor consistente en la búsqueda de una contención multilateral frente a la agresión que Muammar Gadafi dirigió contra sus opositores durante la guerra civil libia de $2011^{88}$.

Un tercer conjunto de preocupaciones sobre los argumentos institucionales de PEтTiT se refiere al grado en el cual él considera ventajoso, desde la perspectiva de la no-dominación, empoderar a los movimientos sociales y las asociaciones cívicas para resistir la política mayoritaria. En la visión de la democracia de PETTIT, es esencial que el pueblo sea «capaz de disputar a voluntad esas decisiones y [...] que, según el resultado de esa disputa — según queden parados sus intereses y sus opiniones relevantessea capaz también de obligar a alterarlas» ${ }^{89}$. En su visión, las asociaciones cívicas y los movimientos sociales sirven como amortiguadores de oposición en contra de la tiranía de la mayoría, al formular quejas y organizarlas como una política contestataria eficaz en pos del cambio progresista. La «primera imagen que nos viene a la cabeza», nos dice PeTtiT, «es la del movimiento popular, la controversia y el debate generalizados, y un progresivo reajuste legislativo» ${ }^{90}$. Como ejemplos cita el movimiento de mujeres, el movimiento verde, el movimiento en favor de los derechos homosexuales, y los movimientos que apoyan a las minorías étnicas y los pueblos indígenas. PETTIT insiste en que «[c]ualquier democracia que tenga que servir a los propósitos republicanos tiene que ser capaz de dar audiencia a alianzas y compromiso mudadizos; tiene que estar abierta a transformaciones profundas y de largo alcance» ${ }^{91}$.

Una de las dificultades que tiene esta idea es la suposición manifiesta de que, en efecto, los movimientos sociales y las asociaciones cívicas se organizarán para apoyar el cambio que PETTIT considera progresista. Es cierto que los movimientos de oposición se han organizado para avanzar las metas que PETTIT enumera, pero también que lo han hecho para promulgar la Proposición núm. 13 en California con el fin de imponer la revocatoria del impuesto federal al patrimonio de los multimillonarios y de proscribir el matrimonio homosexual y la acción afirmativa. En los Estados Unidos, el movimiento más efectivo de esa naturaleza desde 2009 quizás ha sido el del Tea Party, que surgió para resistir la agenda de Barack Obama sobre la reforma al sistema de salud, la legislación ambiental y la regulación financiera. Como sugieren estos ejemplos, no hay ninguna razón particular para suponer, como lo hace PETTIT, que el empoderamiento de los movimientos sociales con el fin de resistir al gobierno democrático en general

${ }^{88}$ Con esto no quiero defender todos los aspectos de la política de la administración Obama frente a Libia. A veces la urgencia moral de una situación amerita una intervención rápida sobre la base de que es mejor pedir perdón que pedir permiso; vid. SHAPIRO, Real World, op. cit., 25, 156-179. Podría decirse que esa situación prevaleció en Libia en marzo de 2011 cuando el régimen de Gadafi estaba amenazando con el exterminio masivo de sus oponentes, pero la misión evolucionó considerablemente después. La política de respetar zonas de exclusión aérea autorizada por el Consejo de Seguridad de la ONU mutó hacia una campaña no autorizada para lograr un cambio de régimen. Para una táctica como esa, con tanto en juego, las condiciones necesarias incluyen una creencia verosímil de que existe una oposición democrática nativa que puede tomar el poder y que sería una mejoría. Tal y como sucedió con el esfuerzo por cambiar el régimen en Irak en 2003, cuando la misión-mutante se puso en marcha en Libia en el verano de 2011, había poca evidencia para apoyar tal creencia. Cuando el régimen de Gadafi se desmoronó a fines de agosto de 2011, en el mejor de los casos el panorama futuro para la democracia en Libia era aún incierto.

89 PeTtit, Republicanismo, op. cit., 243.

90 Ibid., 254.

91 Ibid., 196. 
llevará a un cambio progresista. PETTIT lo reconoce implícitamente en su defensa de las reglas mordaza, diseñadas para despolitizar los debates sobre castigos criminales, al anotar que «las críticas al funcionamiento de la justicia penal ganan audiencia en un foro público politizado, lo que trae consigo un buen número de efectos perniciosos» ${ }^{92}$. PETTIT se refiere a las sentencias condenatorias severas que, según los expertos, no tienen efectos disuasorios ${ }^{93}$. Pero quizás a la gente le importa más la retribución que la disuasión ${ }^{94}$. ¿Quién es PeTTIT para decidir qué asuntos deberían estar sujetos a la impugnación cívica empoderada y cuáles deberían ser removidos del debate político a través de reglas mordaza? Su republicanismo puede ser un manifiesto atractivo para el Partido de los Tipos Sensatos. Pero es dudoso que ofrezca una base política sólida para limitar la dominación.

Creo que PetTit subestima las dificultades de su posición en parte por su fe en la capacidad de la deliberación para canalizar la política en direcciones acertadas. Él supone que, luego de seguir una ronda de deliberaciones o apelaciones de conformidad con los procedimientos apropiados, las personas aceptarán los resultados que las perjudican si ellos favorecen el interés general. «Lo único que [se] necesita es que esa decisión se tome de acuerdo con procedimientos adecuados según sus propias interpretaciones y que haya sido dictada, en última instancia, por un interés que [...] [se] comparta con otros» ${ }^{95}$. Bajo la visión contestataria del proceso democrático de PETTIT, este «está diseñado para que se realicen y se impongan por sí mismas las exigencias de la razón» ${ }^{96}$. Este uso confiado de la voz pasiva puede ser alentador sólo en la medida en que compartamos la fe de PETTIT en que los perdedores en el proceso de disputa aceptarán la legitimidad de su derrota. Uno no tiene que pasar mucho tiempo escuchando a Rush Limbaugh, Sean Hannity, Glen Beck y los líderes del movimiento del Tea Party para darse cuenta de que ellos nunca han tenido la intención de admitir la legitimidad de ningún aspecto de la agenda de la administración Obama, y de que utilizaron todos los recursos que pudieron reunir para descarrilarla tanto como fuese posible. En la medida en que han sido exitosos en esta empresa, ellos se ven a sí mismos como resistentes eficaces de la dominación y, desde la perspectiva de PETTIT, están en lo cierto. Desde mi perspectiva, en contraste, hubiésemos preferido que ellos fracasaran ya que sus intereses básicos no estaban en juego, mientras que sí lo estaban los de quienes podían perder (o no obtener) el seguro de salud, desempleo o pensiones.

PETTIT defiende los foros de disputa en parte porque los considera superiores a una versión de la competencia política basada en la negociación. Él se inspira en la visión de los padres fundadores estadounidenses del siglo XVIII, de acuerdo con la cual «los ciudadanos están en igualdad de exigencias y de poderes» y «los asuntos públicos se deciden por deliberación sobre la base de consideraciones que resultan comúnmente atractivas — no están sesgadas en favor de ningún grupo, ni siquiera en favor del status quo- y el acuerdo sirve como ideal regulativo del modo en que deberían deci-

92 Ibid., 256.

93 Ibid., 256-257.

94 Vid., por ejemplo, W. Berns, «The Morality of Anger», en G. H. Stassen (ed.), Capital Punishment: A Reader, Cleveland, Pilgrim Press, 1998, 15.

${ }_{95}$ PetTit, Republicanismo, op. cit., 258.

${ }^{9}$ Ibid., 261-262. 
dirse las cosas» ${ }^{97}$. Como J. COHEN y HABERMAS (a quien cita de manera aprobatoria a este respecto), PETTIT cree que involucrarse en la deliberación hará que las personas descubran, e incluso quizás fabriquen, el terreno común que se requiere. En contraste, el problema de las disputas negociadas es que «sólo son accesibles a quienes tienen suficiente poder negociador para poder amenazar efectivamente a otras partes; si ustedes quieren forzar un cambio en la negociación, mejor que representen a un grupo de intereses de cierto peso» ${ }^{98}$.

Como defensa de la deliberación en el mundo real, este argumento constituye un salto lógico. Puede ser que la deliberación lleve a las personas a discernir y luego a moverse hacia áreas de común acuerdo, aunque he aducido en otro lugar razones para ser escépticos frente a esta proposición ${ }^{99}$. Pero al abogar por la superioridad de la deliberación sobre la negociación, PETTIT nunca enfrenta el hecho real de que las personas no pueden ser forzadas a deliberar y de que quienes no están inclinadas a deliberar pueden usar los mecanismos deliberativos con el fin de obstruir el cambio y, de ese modo, terminar negociando en la práctica. Por esto, he argumentado que, si queremos poner la deliberación al servicio de la reducción de las formas de dominación que deberían preocuparnos, los derechos a insistir en la deliberación deberían restringirse a aquellas personas cuyos intereses básicos están en juego. Sin duda, esas personas pueden utilizar tales derechos para negociar en lugar de deliberar pero, al menos en ese caso, los intereses que estarían siendo protegidos serían los de quienes son vulnerables de los modos que nos deberían preocupar ${ }^{100}$.

Lo que aquí está en juego puede ilustrarse de manera cruda con el argumento estrechamente relacionado de PETTIT de que los perdedores en el proceso legislativo deberían disfrutar del acceso a foros en los cuales puedan limitar los efectos que consideren perjudiciales de una política aprobada por la mayoría, a través de la «edición» de esa política al momento de su aplicación ${ }^{101}$. Durante 2009 y 2010, los grupos de presión de la banca de inversión en Estados Unidos promovieron un inmenso esfuerzo de cabildeo, que casi resulta exitoso, diseñado para hundir los planes de regulación de la banca de inversión de la administración Obama tras la crisis bancaria mundial de 2008. Estos grupos no lograron descarrilar por completo la regulación, aunque la debilitaron considerablemente al asegurar, entre otras cosas, que los reguladores definirían más adelante muchos de los asuntos más contenciosos relacionados con el comportamiento sistemáticamente riesgoso de los bancos que se consideraban demasiado grandes para fracasar ${ }^{102}$. No se requieren saltos gigantes de la imaginación para predecir que estos

${ }^{9}$ Ibid., 246.

98 Ibid., 245 .

99 SHAPIRO, Estado, op. cit., 41-58.

100 Ibid., 76-77.

$101 \mathrm{Ph}$. PetTit, «Democracy, Electoral and Contestatory», en I. ShaPIRo y S. Macedo (eds.), Designing Democratic Institutions, New York, New York University Press, 2000, 195 (citado en adelante como PETTIT, «Democracy»).

102 Vid. N. Popper, «Banks Step Up Spending on Lobbying to Fight Proposed Stiffer Regulations», The Angeles Times (16 de febrero de 2010), disponible en internet en: The Angeles Times, bttp:/larticles.latimes. com/2010/feb/16/business/la-fi-bank-lobbying16-2010feb16; B. DENNIS y S. MuFSON, «Banks Lobby against Financial Regulatory Overhaul», The Washington Post (18 de marzo de 2010), disponible en internet en: The Washington Post, http://www.washingtonpost.com/wp-dyn/content/article/2010/03/18/AR2010031805370. btml. 
reguladores se convertirán en el objeto de campañas incesantes con el fin de quitarle aun más dientes a la legislación a través de su «edición» al momento de su aplicación. Tras la aprobación en el Congreso de la regulación bancaria en 2010, pregunté a un socio de uno de los bancos de inversión más grandes si a partir de ahora ellos permanecerían fuera del negocio de las transacciones en las que toman posición propia. Su respuesta fue: «Pasarán cinco años antes de que sea claro si podemos eliminar esa porción de la regulación», pero le pareció una buena apuesta confiar en que lo lograrían. En la vida real, en esto consiste la edición de leyes al momento de su aplicación.

Una última característica inquietante de la postura institucional de PETTiT es la suposición que atraviesa sus escritos de que el poder ejercido por los estados es más maligno que el poder ejercido por otros actores, sean ellos individuos poderosos $\mathrm{u}$ otros agentes corporativos. Dado que se establece como un agente colectivo con la capacidad de interferir arbitrariamente en los asuntos de cualquier individuo, el estado constituye una amenaza potencial para todo el mundo. Esto significa que, aunque quienes proponen la no-dominación deberían ver en el estado un instrumento para limitar los efectos malignos de dominium privado, ellos «no dejarán de estar alertas al peligro de conferir al estado el tipo de licencias que traen consigo una forma dominadora de imperium público» ${ }^{103}$. Si su capacidad de acción «está restringida de manera insuficiente o su rango de responsabilidades es demasiado amplio, el gobierno es susceptible de convertirse en una presencia dominadora por derecho propio» ${ }^{104}$.

Esta preocupación lleva a PETTIT a apoyar una lista extremadamente larga de restricciones a la política mayoritaria. Además de los derechos deliberativos y de otros derechos de disputa ya discutidos, PETTIT es un partidario de la multiplicación de los frenos a la acción colectiva a través del bicameralismo, los requisitos supra-mayoritarios, la separación de poderes, el control judicial, el federalismo, los procesos de apelación contra las decisiones administrativas, las medidas ex ante para limitar sus efectos, la independencia de los bancos nacionales, las exenciones y tratamientos especiales para las culturas minoritarias, el traspaso de asuntos políticamente cargados a «cuerpos con conocimientos técnicos», y el uso de reglas mordaza para limitar el mandato de la política electoral. A pesar de su reconocimiento de que los vetos pueden bloquear el cambio legítimo ${ }^{105}$, el análisis que PETTiT hace de estos asuntos parece enteramente ingenuo frente a la literatura sobre los puntos de veto que va desde B. BARRY hasta G. TseELIS, la cual ha dejado en claro que, en la medida en que los jugadores con poder de veto se vuelven más fuertes y los puntos de veto se multiplican, también lo hacen la protección del statu quo y quienes tienen los recursos para aguantar hasta que sus oponentes pierdan fuerza ${ }^{106}$.

Aquí encontramos una curiosa paradoja en la visión de PETTIT. De una parte, él expresa un escepticismo considerable en cuanto a que los actores no estatales sean lo suficientemente poderosos para reducir la dominación de manera efectiva en las

\footnotetext{
103 PeTtit, Republicanismo, op. cit., 198.

104 Ibid.

105 PeTtiT, «Democracy», op. cit., 118-119.

106 B. BARry, Political Argument, London, Routledge \& Kegan Paul, 1965; G. Tsebelis, Jugadores con veto. Cómo funcionan las instituciones políticas, traducido al castellano por J. M. SALAZAR, México, Fondo de Cultura Económica, 2006.
} 
sociedades modernas. Se refiere a esto como la estrategia de «poder recíproco» que, en efecto, depende de los recursos privados y de otros recursos descentralizados como medios para combatir la dominación. PETTIT anota que «[e]stá prácticamente fuera de duda que el movimiento sindicalista promovió la no-dominación de los trabajadores en el mundo industrial del siglo XIX»; sin embargo, insiste en que «sería muy poco razonable» dejarse atraer por su estrategia de acción directa, la cual enfrenta «demasiados problemas como para que pueda tomarse en serio». En cambio, PETTIT alega que «la estrategia de recurrir al Estado [...] parece con mucho la opción más atractiva» ${ }^{107}$. De otra parte, hemos visto que su lista de los mecanismos institucionales preferidos para separar, dispersar, frenar y vetar la acción estatal es tan extensa que es poco probable que tenga un impacto significativo sobre la dominación privada.

Los sindicatos ofrecen un buen ejemplo de esto. Incluso estando organizados y ampliamente apoyados como lo estaban en Inglaterra y los Estados Unidos a mediados del siglo pasado, los sindicatos no podrían de ninguna manera haber disfrutado del éxito que tuvieron sin la gran ayuda ofrecida por la legislación que promovieron los gobiernos laboristas sucesivos en Inglaterra y sin la aprobación de la ley Wagner en los Estados Unidos en 1935. Sin embargo, lo que evisceró la organización laboral en ambos países, que empezó en Estados Unidos en los años cincuenta y despegó en ambos países en los ochenta, fue el menoscabo de esas protecciones legales a instancias de los grupos de interés corporativos y de sus partidarios precisamente a través de las formas de «política basada en la disputa» defendidas por PETTIT.

PETTIT parece estar en desacuerdo consigo mismo. De una parte, está de acuerdo en que la acción eficaz de los gobiernos democráticos es probablemente esencial para cualquier proyecto de erradicación de los sistemas de dominación arraigados. De otra parte, parece temerle tanto a la política democrática y al Estado que quiere confinarlos a cada momento, al insistir en que «[t]odo interés y toda interpretación que guíen la acción de un Estado deben estar abiertos a la crítica procedente del último rincón de la sociedad; y cuando hay disenso, deben adoptarse los remedios apropiados» ${ }^{108}$. Dada la gran cantidad de oportunidades con las que cuentan quienes tienen el tiempo y los recursos de su lado para hacer peticiones especiales, escoger los foros y demorar los procesos en el modelo de PETTIT de poder disperso y frenos institucionales, es difícil imaginar a los Estados del mundo tal y como él los imagina haciendo algo en absoluto, para no mencionar siquiera la tarea de lidiar con sistemas de dominación arraigados. Esta tensión es desconcertante. Es como si, a pesar de toda la atención puesta a la centralidad de la dominación en su teoría, PETTIT no percibiera mucha dominación en el mundo que lo rodea. De manera generosa, PETTIT también parece atribuir su alegre disposición a toda la humanidad. El suyo es un mundo en el cual podemos esperar que la presión generada por la disputa progresista, combinada con la intervención vacilante de un Estado semi-incapacitado, logren que las personas renuncien a posiciones de dominación, al ser persuadidas de que ello beneficia al interés general.

Yo me inclino por una visión más oscura de la condición social humana. Esta supone que las personas en posiciones aventajadas casi nunca renuncian a estas posi-

\footnotetext{
107 PetTit, Republicanismo, op. cit., 131.

108 Ibid., 83.
} 
ciones a menos que el statu quo se vuelva costoso para ellas, y que entre las cosas que debe hacer un gobierno comprometido con la no-dominación es aumentar los costos relevantes del statu quo para los poderosos cuando los intereses básicos de quienes son vulnerables están en juego. La mayoría de las personas en los países pobres y en los países de ingresos medios y la mayoría de las personas pobres y de ingresos medios en los países ricos son vulnerables a una dominación seria en muchas situaciones, ya que sus intereses básicos están o bien comprometidos o bien satisfechos de manera tan precaria que sus tratos con otras personas están inevitablemente colmados de la posibilidad de dominación. En mi opinión, lidiar con esa realidad es el punto de partida de cualquier teoría razonable sobre los arreglos distributivos e institucionales que son exigidos por un compromiso de principio con la no-dominación. El énfasis de PETTIT en el número de elecciones que las personas tienen con independencia de su importancia ignora esto, y su fe en la deliberación cívica para promover la acción social progresista es insuficiente. Su justificación de las instituciones públicas es una receta para proteger el statu quo, que sólo podría ser atractiva desde el punto de vista que compartimos si uno no percibiera que ese statu quo está demasiado cargado de dominación. A este respecto, nuestro desacuerdo tiene menos que ver con el significado de la dominación que con nuestras percepciones sobre el modo en que el poder está distribuido en el mundo y en que funciona la política.

La aprobación absoluta de la esclerosis institucional por parte de PETTIT ha sido una postura convencional entre los pensadores republicanos desde que los fundadores estadounidenses escribieron El Federalista. El miedo a la tiranía de la mayoría los indujo a construir muchas de las características institucionales que PETTIT encuentra tan atractivas en el modelo constitucional norteamericano, en parte porque no había ninguna otra manera de lograr la ratificación de la constitución y en parte como resultado de lo que terminó siendo una convicción errada de que ello prevendría la guerra civil. Se ha vuelto claro, desde entonces, que las instituciones consensuales (consociational) contribuyen poco, si es que contribuyen en algo, a la estabilidad democrática; esas instituciones tampoco limitan la propensión a la tiranía de la mayoría. La evidencia sugiere de manera poderosa que el desarrollo económico es lo que mejor predice la supervivencia de la democracia y que los diferentes tipos de arreglos institucionales parecen tener un impacto insignificante, aunque los sistemas presidencialistas son un poco menos estables que los parlamentarios ${ }^{109}$. Esto difícilmente le hace buena publicidad a los efectos benéficos de la separación de poderes. En lo que respecta a la tiranía de la mayoría, no hay ninguna evidencia de que la adición de cartas de derechos y cortes constitucionales a los sistemas democráticos genere alguna diferencia en relación con la protección de las minorías ${ }^{110}$. Tan imperfectos como pueden ser los sistemas parlamentarios competitivos, ellos resultan ser las democracias más estables y, desde el punto de vista de la protección de las minorías vulnerables, son al menos tan buenos como cualquier otra democracia. Dada la propensión de los arreglos republicanos a proteger los sistemas de dominación arraigados y las minorías poderosas, las razones para rechazarlos en favor de los sistemas parlamentarios me parecen decisivas.

109 Vid. A. PRZEWORSKI et al., Democracy and Development, Cambridge, UK, Cambridge University Press, 2000, 78-186.

110 Vid. I. SHAPIRO, Estado, op. cit., 125-147; I. SHAPIRO, «Tyranny and Democracy: Reflections on Some Recent Literature», Government and Opposition, núm. 43, 2008, 486. 


\section{UNA RECONSIDERACIÓN DE LA NO-DOMINACIÓN}

La no-dominación es la piedra fundante de la justicia. Aunque con frecuencia está conectada a consideraciones igualitarias y a llamados a un tipo de libertad, he defendido la idea de que debería diferenciarse de ambas cosas. Los igualitaristas pueden todavía resistir esta idea alegando, en el espíritu de la literatura en torno a la pregunta «¿igualdad de qué?», que mi argumento me compromete con un principio de igualdad en la no-dominación. Pero esa no es mi visión porque la dominación va de lo trivial a lo trascendental, y he argumentado que solo las formas más serias de dominación merecen la atención del Estado. Esto puede provocar como réplica que en realidad yo favorezco la igualdad en la no-dominación allí donde hay intereses básicos en juego. Pero también resisto esta caracterización, porque incluso dentro del ámbito de los intereses básicos algunas violaciones son peores que otras, y estoy de acuerdo con J. SHKLAR y C. HACKER-CORDON en que la prevención de las formas de crueldad y las penurias más extremas deberían prevalecer sobre el remedio de otros tipos de dominación que involucran intereses básicos ${ }^{111}$.

Esto puede provocar la réplica adicional de que mi principio implícito consiste en igualar la eliminación de las formas más atroces de dominación, pero creo que esto sería trivialmente igualitarista en el mejor de los casos. El punto fuerza el uso ordinario del término igualitarista, y la mayoría de las personas que se consideran igualitaristas no lo reconocerían como tal. Más aun, el punto oculta que la comparación de casos extremos de dominación con frecuencia involucra juicios que se acercan mucho a lo inconmensurable, si es que no son, de hecho, juicios imposibles de formular. Durante los años setenta, los defensores del Partido Nacional en Sudáfrica en ocasiones desviaban las críticas preguntando: ¿por qué atacan el Apartheid cuando hay cosas peores ocurriendo en Uganda? No me quedaba claro entonces, ni me queda claro ahora, que fuese posible evaluar la afirmación incluida en esa pregunta y destinada a dotarla de fuerza retórica. Sin duda, una comparación dispositiva de los dos casos involucraría muchos juicios complejos, muchos de ellos contrafácticos, que harían difícil saber incluso por dónde comenzar.

En todo caso, permitir ser arrastrados hacia el debate comparativo me parecía peor que una pérdida de tiempo. A diferencia de los ejemplos sobre el tranvía, que a veces dan una mala imagen de la filosofía moral, estos casos no estaban conectados entre sí —al menos desde la perspectiva de los perpetradores — ${ }^{112}$. Los males del apartheid no

111 J. SHKLAR, Vicios ordinarios, traducido al castellano por J. UtrilLA, México, Fondo de Cultura Económica, 1990; C. HACKER-CORDÓN, Global Injustice and Human Malfare, tesis doctoral, Universidad de Yale University, 2002 (manuscrito no publicado).

${ }^{112}$ Los problemas relacionados con el tranvía involucran ejemplos hipotéticos de elecciones trágicas, diseñados para producir reflexiones sobre nuestras intuiciones morales. Estos ejemplos involucran típicamente elecciones de HOBSON, como sucede cuando la única manera en la cual pueden ser salvados los pasajeros de un tranvía fuera de control es desviando el tranvía de forma tal que ate a un peatón. A veces los ejemplos son tan artificiosos que es difícil ver cuál es su relevancia para los dilemas morales que las personas enfrentan en la práctica. Vid. Ph. FOOT, «El problema del aborto y la doctrina del doble efecto», en Ph. FOOT, Las virtudes y los vicios y otros ensayos de filosofía moral, traducido al castellano por C. MARTínEZ, México, UNAM, 1994; J. Jarvis Thomson, «Killing, Letting Die, and the Trolley Problem», Monist, núm. 59, 1976, 204; J. Jarvis THOMSON, «The Trolley Problem», Yale Law Journal, núm. 94, 1985, 1395; P. Unger, Living High and Letting 
tenían ninguna relación con la dominación que entonces estaba siendo cometida, hacia el norte, por Idi Amin. Los opositores de ambos regímenes posiblemente enfrentaron elecciones sobre dónde era mejor utilizar sus esfuerzos, pero es probable que esas elecciones tuvieran que ver tanto o más con la evaluación de las posibilidades de éxito en cada lugar que con la determinación de cuál de esos regímenes era en últimas peor. En cualquier caso, los argumentos sobre esas elecciones nunca podrían ofrecer una justificación de los males perpetrados en cada lugar. En vez de permitir ser manipulados por demandas poco honestas en favor de una métrica igualitarista de la equivalencia moral, el mejor curso de acción era confrontar esos males en sus propios términos, mostrando por qué y cómo podían ser erradicados.

Mis propuestas tampoco son igualitaristas, o por lo menos no lo son en un sentido convencional. Más bien, yo veo las dimensiones de poder de las interacciones humanas a través de un lente hirschmanesquiano en el cual hay un balance entre la importancia de aumentar la voz democrática y la importancia de reducir los costos de salida para las personas vulnerables ${ }^{113}$. Por ejemplo, con respecto a las relaciones laborales propongo que allí donde los costos de salida para las personas vulnerables son altos debido a la ausencia de un ingreso social robusto, el gobierno debería insistir en que haya más voz dentro de la compañía, es decir, en que haya salvaguardas más fuertes para los sindicatos y otras protecciones para los trabajadores. De forma similar, con respecto al contexto doméstico, sugiero que un régimen de divorcios que protege a la persona vulnerable al momento de la disolución de un matrimonio hace legítimo que haya un mayor laissez-faire con respecto a lo que sucede durante el matrimonio ${ }^{114}$. Es cierto que yo afirmo que un régimen con un costo bajo de salida y poca regulación es mejor que un régimen con un costo alto de salida y mucha regulación, lo cual me lleva a defender un ingreso social robusto. Pero esto se deriva de dos consideraciones, ninguna de las cuales es igualitarista: mi noción del poder centrada en los recursos y mi presunción general de que, aunque es importante reivindicar los intereses básicos de las personas, siempre es mejor hacerlo de formas que interfieran lo menos posible con lo que sucede al interior de las instituciones y las prácticas civiles ${ }^{115}$.

Apelar a la no-dominación es apelar a un tipo particular de libertad política que los seres humanos tienen el poder de retener o suministrar. Aunque no es intrínsecamente hostil a todas las jerarquías existentes en los asuntos humanos, la no-dominación, tal como yo la entiendo, es sensible al hecho de que las jerarquías legítimas con frecuencia se atrofian y se convierten en sistemas ilícitos de dominación. El desafío institucional consiste en vigilar el potencial de dominación a través de las restricciones democráticas, pero hacerlo de la manera menos intrusiva posible. Esta visión de la no-dominación es política hasta el fondo, y no toma ninguna posición sobre los debates metafísicos más grandes acerca de la posibilidad y el significado de la libertad humana. Tampoco trata la libertad como el summum bonum por el cual la gente puede luchar. Mi teoría adopta un enfoque minimalista sobre la identificación de los intereses humanos que

Die, Oxford, Oxford University Press, 1996; F. KAMm, «Harming Some to Save Others», Philosophical Studies, núm. 57, 1989, 227.

113 A. O Hirschman, Salida, voz y lealtad. Respuestas al deterioro de empresas, organizaciones y Estado, traducido al castellano por E. SuÁreZ, México, Fondo de Cultura Económico, 1977.

114 SHAPIRO, Democratic Justice, op. cit., capítulos 5-6.

115 Ibid., capítulo 2. 
son comunes y sobre la posibilidad de que esos intereses puedan ser rastreados de manera significativa por las instituciones políticas. Se trata de un ideal reactivo que apela a la creatividad humana para diseñar e implementar prácticas que puedan mejorar las fuentes de la dominación en la medida en que ellas surjan. Como resultado, siempre opera en los márgenes, evitando el proyecto de diseñar una estructura básica para la sociedad como un todo.

La no-dominación tal como la he defendido es foucaultiana en el sentido de reconocer que las relaciones de poder son ubicuas a la interacción humana, pero yo desapruebo la negativa de FOUCAULT de establecer distinciones entre los tipos de dominación o de enfrentar preguntas sobre qué hacer con respecto a la dominación. Hacer esto es, en mi parecer, el proyecto constructivo central sugerido por la observación central de FOUCAULT. La no-dominación tal como la defiendo implica enhebrar la aguja del diseño institucional sin depender de las grandes suposiciones sobre la comunicación y la deliberación humanas que infectan los argumentos propuestos por HABERMAS y PetTit. Esta versión de la no-dominación depende de una visión de la libertad que, como la de SKINNER, implica renunciar a la teoría libertaria negativa que heredamos de HoввеS. Pero en lugar de intentar reemplazarla con la visión negativa de la libertad basada en el status con la que simpatiza SKINNER, yo rechazo la dicotomía negativa/ positiva en favor de una visión relacional que implica pensar acerca de la no-libertad en su relación con los agentes, las condiciones restrictivas y habilitantes, las acciones y los sistemas de autorización. Esto respalda el carácter reactivo de mi teoría porque, en lugar de empujarnos hacia las grandes teorías de la libertad, nos dirige a centrarnos en personas, circunstancias, posibilidades e instituciones de autorización específicas para identificar los contornos de la dominación y definir qué hacer con respecto a ella.

En la medida en que las presunciones generales se justifican, estoy de acuerdo con PetTit en que la democratización de las dimensiones de poder de las interacciones humana es el mejor camino a seguir, y esto significa crear mecanismos para la participación y la oposición efectivas. Pero difiero de PETTiT al sostener que la forma de esos mecanismos y su nivel de intrusión deberían depender de la naturaleza de los intereses en juego, y que los intereses básicos deberían funcionar como el punto de referencia para otorgar derechos. Y dado que estoy de acuerdo con la afirmación de PETTIT de que erradicar los sistemas de dominación arraigados normalmente requerirá la acción eficaz de los estados, estoy en desacuerdo con su aprobación de las instituciones republicanas, que están repletas de puntos de veto y otros elementos consensuales. Estas instituciones pueden hacer que sea demasiado fácil obstruir el cambio para quienes controlan los sistemas arraigados de dominación y, en todo caso, no producen los beneficios de proteger a las minorías vulnerables de la tiranía de la mayoría que con frecuencia se reputan de las instituciones republicanas.

Es bien sabido que J. MADISON hizo una defensa incisiva de estas instituciones en El Federalista. En ese momento tenía treinta y seis años, y la mayor parte de su experiencia política yacía delante de él. Quizás por esa razón mucho de lo que escribió sobre partidos políticos y competencia en El Federalista parece escrito por alguien que está intentando aprender nadar caminando alrededor de un lago mientras discute la teoría de la natación. Lo que es menos conocido es que el MADISON maduro rechazó el pensamiento republicano que se le suele atribuir y al cual apelan PETTIT y otros repu- 
blicanos contemporáneos. Sus años en los bruscos avatares de la política del Congreso, como secretario de estado y como el cuarto presidente de Estados Unidos convencieron a Madison de que la competencia democrática es la mejor garantía disponible de los valores que los republicanos buscan proteger. En 1883, tres años antes de su muerte, fue inequívoco al decir: «Si los gobiernos mayoritarios... son los peores Gobiernos [...] quienes piensan y dicen eso no pueden permanecer dentro del marco de la fe republicana. Ellos deben o bien unirse a los discípulos confesos de la aristocracia, la oligarquía o la monarquía, o bien buscar una Utopía que exhiba una homogeneidad perfecta de intereses, opiniones y sentimientos que aún no ha sido hallada en ningún lugar de las comunidades civilizadas» ${ }^{116}$. La evidencia posterior sugiere que el MADISON maduro tenía razón en que la competencia democrática ofrece la mejor esperanza para mitigar la dominación. Como resultado, trabajar para protegerla y expandirla es el mejor camino para quienes conciben la no-dominación como la piedra fundante de la justicia.

116 J. MADISON, «Majority Governments», en Letters and Other Writings of James Madison, vol. 4, Philadelphia, PA, J. P. Lippincott, 1865, 332 (versión en castellano de la traductora de este artículo). Para una discusión adicional, vid. SHAPIRO, Real World, op. cit., 38-67. 